\title{
Effect of Buoyancy Loads on the Tsunami Fragility of Reinforced Concrete Frames Including Consideration of Blow-out Slabs
}

\section{Marta Del Zoppo ( $\square$ marta.delzoppo@unina.it )}

Universita degli Studi di Napoli Federico II https://orcid.org/0000-0002-3396-9825

\section{Tiziana Rossetto}

University College London

\section{Marco Di Ludovico}

University of Naples Federico II: Universita degli Studi di Napoli Federico II

\section{Andrea Prota}

University of Naples Federico II: Universita degli Studi di Napoli Federico II

\section{Research Article}

Keywords: tsunami engineering, fragility, uplift loads, VDPO-BI, blow-out slabs, breakaway infill walls

Posted Date: December 21st, 2021

DOI: https://doi.org/10.21203/rs.3.rs-1178101/v1

License: (a) (i) This work is licensed under a Creative Commons Attribution 4.0 International License. Read Full License 

out slabs

${ }^{1}$ Post-Doctoral Research Fellow, Department of Structures for Engineering and Architecture, University of Naples Federico II, Italy

${ }^{2}$ Full Professor, EPICentre, Department of Civil, Environmental and Geomatic Engineering, University College London, United Kingdom

${ }^{3}$ Associate Professor, Department of Structures for Engineering and Architecture, University of Naples Federico II, Italy ${ }^{4}$ Full Professor, Department of Structures for Engineering and Architecture, University of Naples Federico II, Italy *corresponding author: marta.delzoppo@unina.it

\section{Abstract}

Currently available performance-based methodologies for assessing the fragility of structures subjected to tsunami neglect the effects of tsunami-induced vertical loads due to internal buoyancy. This paper adopts a generalized methodology for the performance assessment of structures that integrates the effects of buoyancy loads on slabs during a tsunami inundation. The methodology is applied in the fragility assessment of three case-study frames (low, mid and high-rise), representative of existing masonry-infilled reinforced concrete (RC) buildings typical of Mediterranean region. The paper shows the effect of modelling buoyancy loads on damage evolution, structural performance and fragility curves associated with different structural damage mechanisms for RC frames with breakaway infill walls including consideration of blowout slabs. The outcomes attest that the predominant failure mechanism of selected case-study is the brittle shear failure of seaward columns, which is slightly affected by buoyancy loads. When brittle failure is avoided, buoyancy loads significantly affect the damage evolution during a tsunami, especially in the case of structures with blow-out slabs. The rate of occurrence of slabs uplift failure increases with the number of stories of the building but only slightly affects the fragility curves of investigated structures. However, it can significantly increase their vulnerability, affecting both direct and indirect costs deriving from the repair of the damaged interior slabs.

Key words: tsunami engineering; fragility; uplift loads; VDPO-BI; blow-out slabs; breakaway infill walls.

\section{Introduction}

Far-fault tsunami events have a low frequency but can induce high human and economic losses on coastal communities (Ghobarah et al. 2006, Chock et al. 2013, Paulik et al. 2019). The fragility assessment of existing assets against tsunamiinduced loads is fundamental for estimating the resilience of the built environment to such hazard and to inform disaster 
the recent ASCE 7-16 Standard (2017) for the design of tsunami vertical shelters. However, the Standard does not explicitly state how to apply tsunami-induced loads on buildings in a non-linear structural analysis approach for the fragility assessment of structures. Recent studies have proposed numerical tools for the performance or fragility assessment of structures during a tsunami inundation under tsunami-induced drag loads (Attary et al. 2017, Petrone et al. 2017, Alam et al. 2018, Del Zoppo et al. 2021a, Baiguera et al. 2021). Only a very few studies in tsunami engineering have considered uplift pressure due to buoyancy in their structural analyses. Tokimatsu et al. (2016) and Chaudhary et al. (2017), among few others, have looked at buoyancy loads on structures with main focus on buoyancy acting at foundation level to assess the resistance against global overturning of buildings. The latter is a typical collapse mechanism for watertight buildings, buildings with strong slabs-on-grade or buildings with small opening ratios, as observed after the 2011 Tohoku tsunami (Chock et al. 2013). In buildings with breakaway infill walls (i.e., walls that fail out of their plane during a tsunami inundation), the magnitude of buoyancy loads acting at foundation level after the failure of exterior cladding is relatively low due to the limited enclosed space inside the structure, and global overturning is unlikely to happen ${ }^{1}$. However, internal buoyancy induces uplift loads on elevated slabs due to enclosed spaces inside the structure, air trapped below floors (i.e., air pockets) and submerged structural members ${ }^{4}$ that have been largely ignored in tsunami fragility and vulnerability analysis performed so far. Tsunami buoyancy induced loads may represent a source of damage for elevated slabs of structures with breakaway walls in coastal area, causing the uplift failure of blow-out slabs (Ghobarah et al. 2006, Saatcioglu et al. 2006). This damage mechanism has never been included in past analytical fragility and vulnerability studies. Buoyancy can also cause a reduction of axial load in vertical members, with a consequent reduction of flexural and shear capacity that can lead to premature local and global failure mechanisms for the building (Del Zoppo et al. 2019, Del Zoppo et al. 2020). Yet, the effect of tsunami-induced vertical loads on elevated slabs due to internal buoyancy has not been properly addressed in the literature regarding the structural assessment of buildings subjected to tsunami. Few experimental tests in hydraulic flumes have been performed to assess uplift forces on slabs and bridge decks induced by buoyancy (Hartana and Murakami 2015, Wüthrich et al. 2018, Alam et al. 2020). These studies represent a valuable simulation of the effect of waves on elevated slabs in terms of loads and pressure. However, such findings have not yet been integrated into tsunami structural analysis methodologies, and empirically validated load equations are lacking.

This paper adopts a generalized analysis methodology, called Variable Depth Pushover for Breakaway Infilled frames (VDPO-BI), for including buoyancy loads with lateral loads in the tsunami performance and fragility assessment of structures. In the VDPO-BI, the definition of buoyancy loads provided by the ASCE 7-16 (2017) is adopted, and a nonlinear static analysis approach is used that simultaneously simulates the effects of drag and buoyancy induced loads on a building structure for increasing tsunami inundation depth. A realistic simulation of the distribution of uplift loads on 
elevated slabs during a tsunami inundation is proposed within the VDPO-BI analysis methodology as a function of the out-of-plane failure of breakaway infill walls and the uplift failure of elevated slabs. The VDPO-BI is adopted to investigate the significance of the inclusion of buoyancy loads and blow-out slabs on the tsunami fragility of reinforced concrete (RC) frames associated to selected local and global structural damage mechanisms. Three case-study masonry infilled RC frames typical of the Mediterranean region with different heights are adopted to develop fragility curves at single building level, pointing out the correlation between buildings height and effects of buoyancy loads on RC structures. Structural damage levels associated to vertical members (i.e., columns), horizontal members (i.e., slabs) and the global structure are defined based on the HAZUS Tsunami Technical Manual Guidance (FEMA 2017), and the effects of buoyancy and blow-out slabs on the fragility curves for the case-study frames are presented and discussed.

\section{Research background and significance}

Only few existing studies have proposed numerical tools for assessing the capacity or the fragility of structures under tsunami onshore flows. Most of these studies rely on structural analysis methodologies derived from earthquake engineering and merely adapted to the case of tsunami lateral loading (i.e., ignoring buoyancy) (Attary et al. 2017, Alam et al. 2018). However, the structural response under tsunami loading differs fundamentally from the seismic performance of buildings. Tsunami long-period waves do not significantly excite a dynamic response in structures, and the tsunami structural response is force-based (Rossetto et al. 2017). Consequently, ductility does not play a fundamental role in the performance assessment of structures due to the long duration of tsunami loads inducing structural collapse beyond peak capacity. Furthermore, the distribution of lateral pressures induced by tsunami on-shore flows has higher magnitude at the bottom of the structure, with a large concentration of lateral loads on first storey level components. Nonlinear static and dynamic structural analysis methodologies specifically developed for the tsunami fragility assessment of structures have been proposed for the first time in Petrone et al. (2017). One such tool is the nonlinear static procedure named Variable Depth Pushover, VDPO. In the VDPO, the tsunami inundation depth $\left(H_{w}\right)$ at the site of the structure is monotonically increased, with the tsunami-induced loads calculated assuming a constant Froude number, until the peak strength is reached. The VDPO methodology has been developed for assessing the performance of buildings subjected to tsunami-induced lateral loads distributed along the seaward columns, hence neglecting internal buoyancy loads. This under the assumption that buildings are watertight, which is representative of new-designed buildings with tsunamiresistant external cladding. However, post-tsunami surveys reveal that exterior claddings of existing RC buildings (i.e., commonly masonry infill walls) are particularly subject to out-of-plane failure during inundation. To assess the performance of structures with such tsunami breakaway claddings (or breakaway infill walls), an equivalent VDPO analysis for breakaway infilled frames has been investigated in Del Zoppo et al. (2021a) to simulate the effect of tsunami breakaway walls failure on the structural performance. In the latter, only tsunami-induced lateral loads are again 
accounted for during the performance assessment. However, in real life, in the case of buildings with breakaway walls, the tsunami flow induces also uplift loads on elevated slabs due to internal buoyancy. Preliminary studies have been conducted by the authors of the two methods to assess the significance of including buoyancy loads in the structural performance assessment of RC frames with breakaway infill walls (Del Zoppo et al. 2019, Del Zoppo et al. 2020). These preliminary studies highlighted the importance of buoyancy loads and have motivated this study, which systematically investigates the influence of buoyancy in the context of common RC buildings' response and extends this to their fragility assessment including the uplift failure of slabs, aspect that has never been investigated before.

Del Zoppo et al. (2021a) proposed a first version of the Variable Depth Pushover for Breakaway Infilled frames (VDPOBI) approach, in their analysis of a Sri Lankan school building. The focus was the investigation of the effects of infill walls on the overall structural response of the school building, with significant effort expended on how to account for the failure of infill panels on the tsunami loading. In this first version of VDPO-BI a simplified representation of buoyancy loads (from air pockets and submerged slabs) was included for the performance assessment of school buildings. The VDPO-BI methodology presented in the current paper constitutes a significant improvement over the methods previously presented by the authors. It considers both tsunami-induced lateral and vertical buoyancy loads in a systematic and detailed way for the performance and fragility assessment of generic frame structures with breakaway infill walls. The VDPO-BI is herein adopted to investigate for the first time the effect of buoyancy loads on the tsunami fragility of existing RC structures typical of Mediterranean regions for different damage levels, explicitly accounting for the uplift failure of interior slabs (i.e., blow-out slabs) due to tsunami buoyancy. The latter is fundamental, as the failure (or not) of these elements significantly affects the buoyancy loads attracted by the building in tsunami, and hence the local and global structural performance. The VDPO-BI analysis combines both lateral and vertical forces induced by a tsunami on structures, and the focus aim is to point out the effect of uplift loads on the fragility of structures under tsunami.

\section{Performance assessment methodology}

The performance of existing RC buildings to tsunami loads is herein investigated by means of refined FEM analyses performed through the generalised VDPO-BI. In the following, the models selected to simulate lateral and vertical tsunami on-shore flows on structures are first illustrated; then, the VDPO-BI procedure is briefly presented to assess the performance of RC frames with breakaway infill walls and blow-out slabs.

\subsection{Tsunami-induced loads on structures}

Tsunami-induced lateral loads on structures mainly consist of unbalanced hydrostatic pressure, hydrodynamic or drag pressure, bore forces and debris impact loads, while vertical loads are mainly related to hydrostatic buoyancy and hydrodynamic surge (ASCE 7-16 2017). Many of these loads are impulsive and highly transient in nature, and hence are neglected in the VDPO-BI. Indeed, in the VDPO-BI analysis the tsunami is simulated as a steady state flow (hydrostatic 
and hydrodynamic loads), and the initial bore phase is ignored ${ }^{7}$. Impact loads are extremely short duration impulsive loads and cannot be represented by pushover analysis. In the context of ASCE 7, the hydrodynamic and hydrostatic loads need not be combined with the debris impact loads because of the low probability of simultaneous occurrence of the maximum of each type of loading (Robertson 2020). Soil erosion and scour induced by the tsunami flow are also neglected in this study. Lateral and buoyancy induced loads on structures considered in the VDPO-BI are further discussed in next sections.

\subsubsection{Lateral loads}

Lateral loads in the form of unbalanced hydrostatic and hydrodynamic pressures are considered acting on vertical components of a structure (i.e., infill walls and columns). Although in the VDPO-BI any assumption can be made as to the lateral load formulation and pressure distribution applied to the structure, in this paper the lateral load equations proposed by Foster et al. (2017) are used. These equations are chosen as they have been empirically validated with recent experimental investigations performed in hydraulic flumes. According to Foster et al., the overall lateral tsunami force has different formulations as a function of the flow regime, which is described by the Froude number (i.e., $\mathrm{Fr}=$ $u / \sqrt{g H_{w}}$, with $u$ the flow velocity) as reported in the following:

where $F_{f} / b$ is tsunami force per unit width (i.e., $b$ is the impact surface width), $\rho$ is the sea water density $\left(1.2 \mathrm{t} / \mathrm{m}^{3}\right.$ in order to account for suspended sediment), $g$ is the gravitational acceleration, $H_{w}$ is the tsunami inundation depth, $C_{D}$ is the drag coefficient for the building and $\lambda s$ is the leading coefficient for steady flows. The leading coefficient is computed as a function of the blocking ratio, $B / w$ (with $B$ the building width, $w$ the width of the flume), as follows:

The blocking ratio is representative of the density of the urban context that affects the flow properties. In a subcritical regime, the Foster et al. equation represents the drag load component. Conversely, in a chocked regime, the overall tsunami force includes both unbalanced hydrostatic and drag loads. Hence, drag loads in the chocked regime are herein computed as the difference between the tsunami force from Equation (1) and the hydrostatic load, computed according to the ASCE 7. Drag loads are applied on the building assuming a uniform pressure distribution, as prescribed by the ASCE 7. Unbalanced hydrostatic loads acting on seaward structural and non-structural members before the failure of breakaway infill walls are applied with a triangular pressure distribution. In the VDPO-BI, a constant relation between flow depth and flow velocity is assumed during the analysis by assuming a constant Froude number. This means that flow velocity increases with the inundation depth during the analysis. 
Buoyancy loads on structures are related to the volume of water displaced during the tsunami inundation, according to Archimedes' principle. Watertight structures or structures with small opening ratios develop large hydrostatic buoyancy loads below the grade of the building due to the enclosed space inside the structure, leading to global overturning mechanisms. Instead, in buildings with breakaway infill walls, buoyancy-induced vertical loads act mainly on interior elevated slabs after the failure of breakaway cladding. Empirically validated models to compute tsunami buoyancyinduced vertical loads on structural components are currently missing. Hence, in this study, the guidance provided in the ASCE 7-16 provisions and by Roberston (2020) are followed. Note that, although the ASCE 7-16 identifies such buoyancy loads on elevated slabs, their inclusion in the design procedure of structures and local checks on slabs as a function of the inundation depth and the damage condition of exterior cladding is currently lacking in the code. Hydrostatic buoyancy-induced loads during tsunami inflow are composed of several components, as shown in Figure 1 and summarized here:

- Buoyancy due to air pockets: air pockets trapped below elevated slabs, for instance air entrapped between

where $h_{\text {beam }}$ is the net height of the beams with respect to the slab, $\rho$ is the sea water density, $g$ is the gravitational acceleration.

where $h^{*}$ is the height of the enclosed volume, computed as the net distance between the top of the slab and the tsunami inundation depth. This load component strictly depends on the out-of-plane capacity of exterior walls in perimetral frames. Indeed, after the failure of exterior walls, the water is allowed into the building relieving this buoyancy effect. 


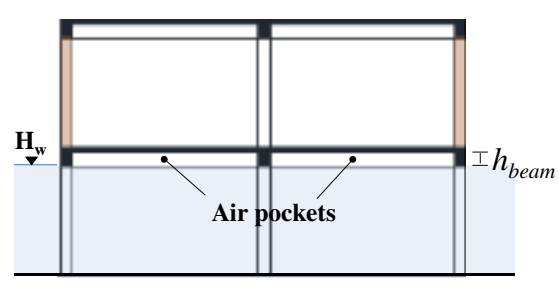

(a)

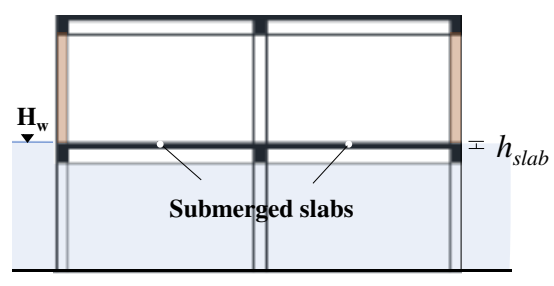

(b)

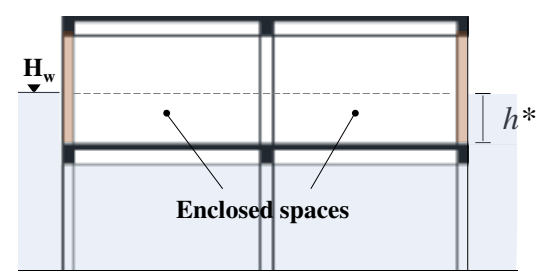

(c)
183

184 185

Figure 1. Buoyancy-induced uplift loads on elevated slabs: air pockets (a), submerged slabs (b) and enclosed spaces (c).

During the tsunami drawdown phase, the elevated floor slabs below the tsunami inundation depth may be subjected to an additional surcharge load due to residual water retained inside the building. This water surcharge is in addition to dead loads and may cause structural damage and failure. The drawdown phase is not considered in the present study and this load component is not considered further here.

Hydrodynamic uplift loads consist in impulsive pressures caused by bore. According to ASCE 7-16 provisions, this load component can be assumed as a minimum average uplift pressure of $20 \mathrm{psf}\left(0.958 \mathrm{kN} / \mathrm{m}^{2}\right)$ applied to the soffit of the slabs submerged during the tsunami inflow. However, according to the code, this uplift load component should be considered as an additional load case to any other hydrostatic buoyancy effects for the design of tsunami-resistant slabs. Since hydrostatic buoyancy loads are much higher than the minimum average hydrodynamic uplift pressure, the latter is neglected in this study.

It should be noted that tsunami buoyancy-induced uplift loads are only a function of the tsunami inundation depth and, differently from lateral loads, do not depend on other tsunami parameters such as the flow velocity (and therefore Froude number).

\subsection{VDPO-BI analysis}

The generalized VDPO-BI analysis simulates the actual distribution of tsunami-induced loads on structural and nonstructural components during the inflow inundation. In the analysis, the tsunami inundation depth, $H_{w}$, at the site of the structure is monotonically increased up to failure. At each step of inundation depth, the procedure explicitly integrates the tsunami-induced lateral and buoyancy loads acting simultaneously on the structure into the nonlinear incremental analysis. Hydrodynamic tsunami loads on structures are hence simulated trough a static analysis procedure (Petrone et al. 2017). Some steps of the VDPO-BI including blow-out slabs are depicted in Figure 2. It should be noted that the analysis methodology involves only the superstructure, and assumes the structure to be rigidly fixed to the ground. 
In the case of frames with breakaway infill walls, the distribution of tsunami-induced loads on structural components strongly depends on the integrity of the infill panels. The inundation depth causing the out-of-plane failure of the walls in the plane normal to the tsunami flow direction is here termed $H_{O O P}$. Before the out-of-plane failure of the infill walls is reached (i.e., $H_{w}<H_{O O P}$ ), lateral loads are assumed to act solely on the exterior of the building, and hence, infill walls and seaward columns only are directly loaded by tsunami-induced lateral loads, see Figure 2a. In this phase, uplift loads caused by buoyancy develop below the grade of the building and act on the foundation system. Such uplift loads may cause the global overturning of the building, especially when shallow foundations are used. However, given the low capacity of breakaway infill walls, buoyancy loads on foundation are relatively low in this phase and are therefore ignored in the analysis. Before the failure of exterior infill walls, unbalanced hydrostatic loads locally act on seaward structural and non-structural components. Once the exterior infill walls fail, the water is free to enter the ground floor, inducing lateral drag loads on both exterior and interior columns, see Figure $2 b$, while hydrostatic loads are globally balanced. When the inundation depth overcomes the soffit of the first story beams, internal buoyancy due to air pockets generates uplift loads on slabs (computed as in Equation 3 and 4), see Figure 2b. These act on the structure simultaneously to the lateral loads. For water depths exceeding the first story slab, additional uplift loads caused by buoyancy due to submerged slabs and enclosed spaces will act on the first story slab (Equation 5), as reported Figure 2c. This uplift load component increases with the inundation depth until the failure of the second story infill walls is reached. Then, uplift loads due to enclosed spaces are relieved, see Figure 2d. Buoyancy due to air pockets and other components of internal buoyancy are instead assumed to continue to act on the structure as the water depth continues to rise. The same process of uplift load application and release is repeated for the other slabs in the structure when the inundation depth reaches and exceeds their elevation. The VDPO-BI analysis stops when the maximum lateral capacity of the structure under tsunami loads is reached.

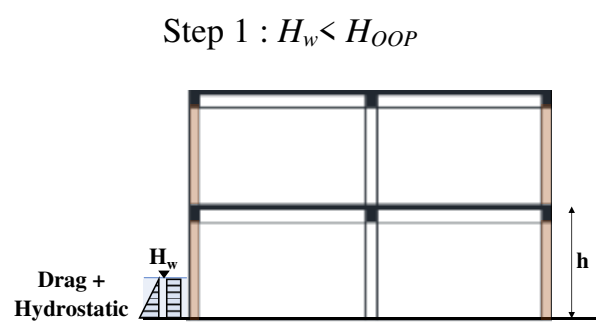

(a)
Step $2: H_{O O P} \leq H_{w}<h$ - $h_{\text {beam }}$

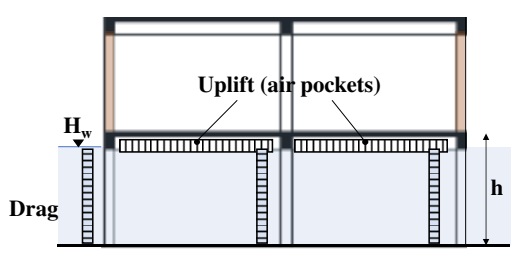

(b)

Step $3: h$ - $h_{\text {beam }} \leq H_{w}<h+H_{O O P}$

Step $4: h+H_{O O P} \leq H_{w}<2 h$ - $h_{\text {beam }}$ 


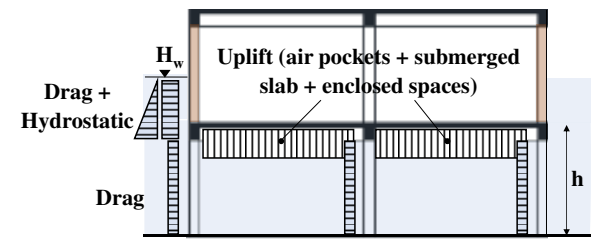

(c)
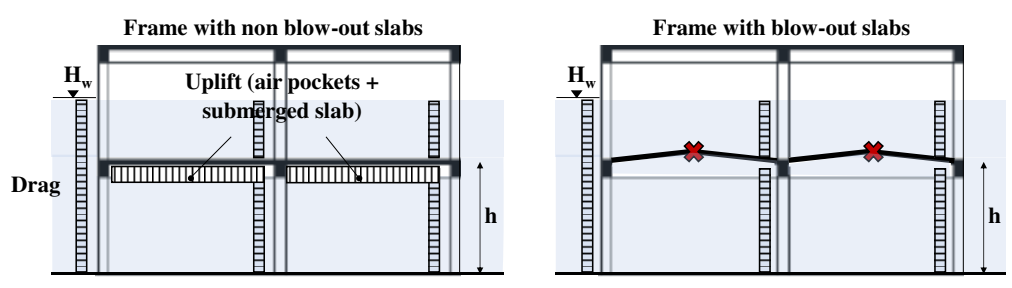

(d)

Figure 2. Steps of the generalized VDPO-BI analysis including blow-out slabs.

The VDPO-BI analysis is force-controlled. The tsunami-induced lateral and uplift loads are applied on structural components as load time-histories, where each time step is associated to a value of tsunami inundation depth. To account for the failure of the infill wall and slabs, the value of inundation depth at which the capacity of infill walls and slabs are reached is first calculated, as discussed in Section 4.2. The time histories for each structural node are then computed in advance of the VDPO-BI analysis, considering the damage condition of both the infill walls (see Figure 2) and slabs for the inundation depth associated with each time step, so determining the appropriate area over which water pressures act. The magnitude and distribution of uplift loads on slabs change during the VDPO-BI analysis due to the development of the different components of internal buoyancy, as a function of the inundation depth and infill walls damage condition. To demonstrate the evolution of buoyancy-induced loads during a tsunami inundation, the uplift loads generated on the first story slab for a generic frame are shown in Figure 3. For this preliminary application, gravity loads are assumed 5 $\mathrm{kN} / \mathrm{m}^{2}$, the beam depth is assumed $650 \mathrm{~mm}$, the slab thickness is $240 \mathrm{~mm}$ and the interstory height is assumed $3 \mathrm{~m}$. The different uplift load components acting on the slab are plotted in Figure $3 \mathrm{a}$ and Figure $3 \mathrm{~b}$ along with the overall vertical load for increasing inundation depth under the hypothesis of strong infill walls (high out-of-plane capacity, $H_{O O P}=2.5$ m) and weak infill walls (low out-of-plane capacity $H_{O O P}=1.0 \mathrm{~m}$ ), respectively. It is observed that even in the case of weak infill walls (which reduces the enclosed space component of uplift loads on the slabs), the buoyancy-induced uplift loads are larger than the gravity loads (i.e., higher than $5 \mathrm{kN} / \mathrm{m}^{2}$ but in the opposite direction in the example of Figure 3 ). This means that high negative bending moments are induced at the midspan of slabs. Slabs that are not designed to sustain such kind of solicitation may fail. Such slabs are termed blow-out slabs in this paper. The uplift failure of slabs is explicitly considered in the VDPO-BI analysis, see Figure 2d. Indeed, if the buoyancy-induced uplift loads overcome the capacity of the elevated slab during the incremental analysis, it is assumed that the slab has failed in all bays of the structure at that story level. In this case, vertical loads (both gravity and uplift loads) are no longer applied to that floor slab during the VDPO-BI. More details on the calculation of slab uplift failure are provided in Section 4.5. 


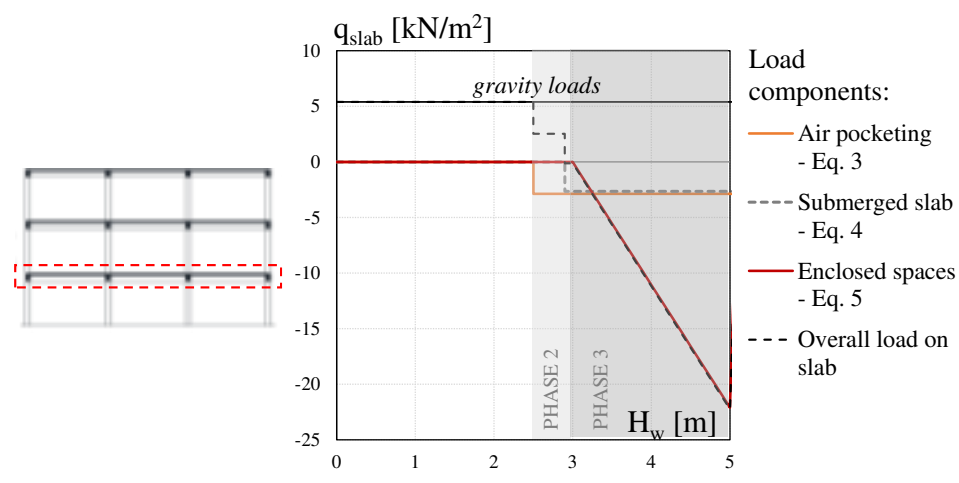

(a)

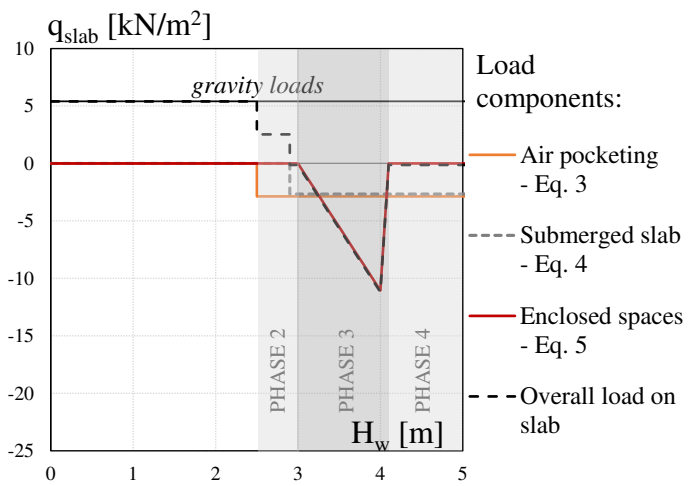

(b)

Figure 3. Tsunami buoyancy-induced uplift loads on slabs for (a) strong infill walls with high out-of-plane capacity $\left(H_{O O P}\right.$ $=2.5 \mathrm{~m})$ and $(\mathrm{b})$ weak infill walls with low out-of-plane capacity $\left(H_{O O P}=1.0 \mathrm{~m}\right)$.

Tsunami-induced lateral loads are applied on structural and non-structural components in proportion to their impacting surface width, $b$. If the exterior infill walls are undamaged, $b$ is equal to the infill length (i.e., bay width) for central columns and half infill length for corner columns. In such a case, lateral loads (i.e., unbalanced hydrostatic and drag) are applied to seaward structural components only, as depicted in Figure 4a, assuming a perfect shear connection between $\mathrm{RC}$ frame and infill walls. Conversely, if the exterior infill walls in the plane normal to the tsunami direction are failed, lateral loads (i.e., drag) are applied to both exterior and interior structural components and should account for the effects of drag amplification and damming debris accumulation.

According to ASCE 7-16, hydrodynamic loads acting on single structural components should be amplified by a drag coefficient, $C_{d}$, that depends on the geometry of the components and the closure ratio. Following the ASCE 7-16 (2017), $C_{d}$ is assumed equal to 2 for rectangular columns in buildings with a closure ratio less than 0.2. Higher drag coefficients need to be used for structures with greater closure ratios to account for the increase in flow velocity inside the building. Hence, after the failure of breakaway infill walls, the impacting surface width $b$ will be equal to the column width amplified by the drag coefficient for both exterior and interior columns. It is assumed that partitions, given their lower thickness and out-of-plane capacity with respect to exterior infill walls, suddenly fail when the exterior walls fail and the water enters the building. The width of the column $\left(b_{\text {column }}\right)$ may also comprise any residual portion of masonry walls that remain attached to the frame, depending on the type of connection between masonry and surrounding columns for the specific structure (Del Zoppo et al. 2021a). The contribution of residual portion of masonry attached to frame should be treated as an uncertainty and is neglected in this preliminary analysis. 
Damming debris are described in the ASCE 7-16 as waterborne debris that may accumulate on the front of the building after the failure of breakaway infill walls, increasing the impacting surface for seaward structural components. It is not clear if this damming debris accumulation should be considered only for the first storey level, where major debris accumulation is expected, or for the entire height of the building. To account for the effect of damming debris accumulation in the performance and fragility assessment of buildings with the VDPO-BI, the impacting surface width $b$ for seaward components can be computed as the bay width multiplied by a factor $C_{c}$, representing the closure ratio (Figure 4b). The minimum closure ratio allowed by the ASCE 7-16 for the design of tsunami-evacuation buildings accounting for the effect of openings and damming debris is 0.7 . This closure ratio can be reduced to 0.5 for the case of open structures (ASCE 7-16). However, debris accumulation is highly aleatory, and $C_{c}$ should be treated as un uncertainty for the development of fragility curves, being the probability of damming debris generation a function of the environmental conditions at the site of the structure and of the tsunami flow characteristics.

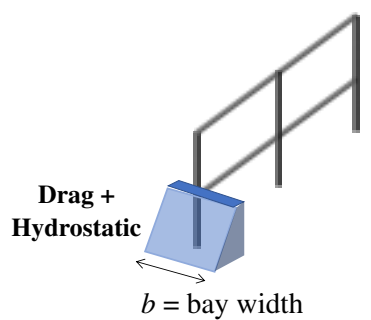

(a)

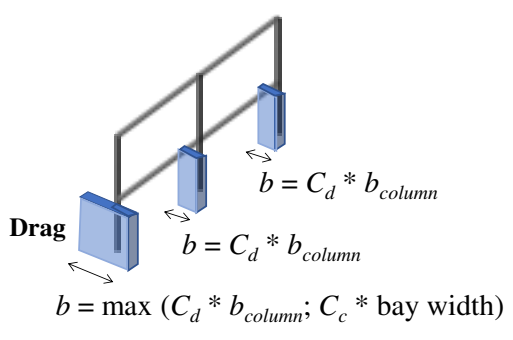

(b)

Figure 4. Impacting surface for tsunami-induced lateral loads accounting for drag amplification and damming debris accumulation: (a) undamaged exterior infill walls and (b) exterior infill walls broken away.

\section{Performance and fragility curves of case-study frames}

To assess the significance of buoyancy-induced loads on structural response under tsunami inundation, the generalized VDPO-BI is applied in the performance and fragility assessment of three case-study frames representative of existing residential buildings in Mediterranean region. A damage scale is defined for the performance assessment that considers local and global damage mechanisms. Furthermore, fragility curves are derived for the case study buildings, considering uncertainty in demand and capacity parameters. The tsunami fragility assessment is conducted under three scenarios with different assumptions on uplift loads and slabs failure, as summarized in Table 1. Details about the definition of casestudy frames, finite element modelling, damage levels and uncertainties selected for this study are discussed in the following. 
Table 1. Scenarios for performance and fragility assessment.

\begin{tabular}{|c|c|c|c|}
\cline { 2 - 4 } \multicolumn{1}{c|}{} & Uplift loads & Blow-out slabs & Breakaway infill walls \\
\hline Scenario $i$ & $X$ & $X$ & $\checkmark$ \\
\hline Scenario $i i$ & $\checkmark$ & $X$ & $\checkmark$ \\
\hline Scenario iii & $\checkmark$ & $\checkmark$ & $\checkmark$ \\
\hline
\end{tabular}

303

\subsection{Case-study frames}

The case-study consist of three RC frames with different number of stories representing the central frames of a 3D residential building with unreinforced masonry infill walls. The buildings are defined with a simulated designed process following the Italian Royal Decree n. 2239 (1939), to be representative of typical existing RC structures built before the 1980s in the Mediterranean area. The selected frames represent typical low-rise (i.e., 3 story), mid-rise (i.e., 6 story) and high-rise (i.e., 9 story) existing structures. The buildings are regular in plan and elevation, and Figure 5 summarizes building plan data along with frames relevant structural details. Concrete with characteristic compressive strength $f_{c k}=$ $20 \mathrm{MPa}$ and reinforcement of characteristic yield stress $f_{y k}=380 \mathrm{MPa}$ are used for design. Further information about the design procedure for case-study frames is reported in Del Zoppo et al. (2021a). A concrete cover of 20 mm is adopted. The transverse reinforcement was not regulated in old design codes, and the stirrup spacing observed in gravity-design buildings before ' 80 s typically ranges between $200-250 \mathrm{~mm}$. For the case-study frames, $8 \mathrm{~mm}$ bars diameter spaced at 200 $\mathrm{mm}$ are selected as transverse reinforcement for columns and beams based on typical construction practice, ensuring that the structural behaviour of such components under static and seismic conditions is governed by flexure.

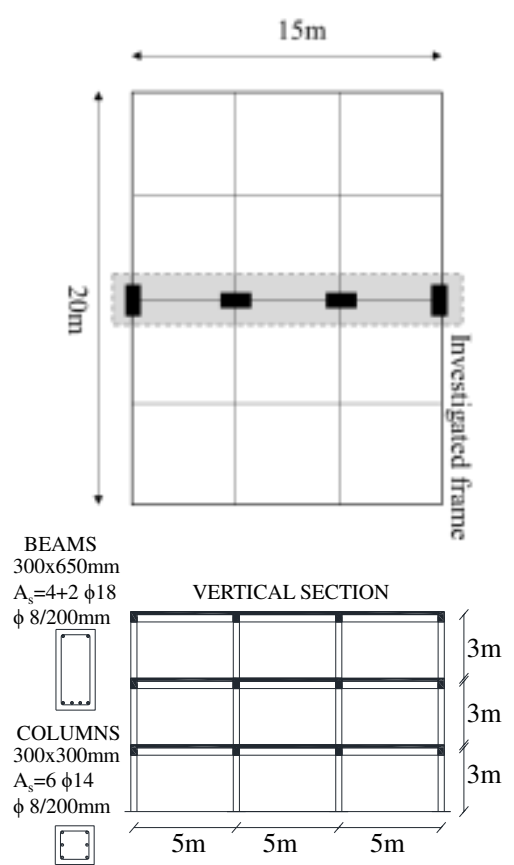

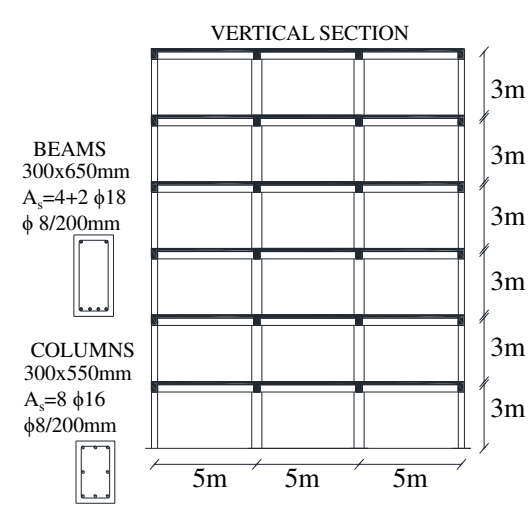


320 The interior slab typology typical of such existing structures consists in a cast-in-place RC ribbed slab, with constant joists dimensions (height $20 \mathrm{~cm}$, width $10 \mathrm{~cm}$ and spaced $50 \mathrm{~cm}$ ) and with a cover concrete layer of $4 \mathrm{~cm}$ thick. Among the joists, hollow clay masonry blocks having a lightening function for the slab are assumed and commonly used in the Mediterranean area, see Figure 6a. for thermal insulation, see Figure $6 b$.

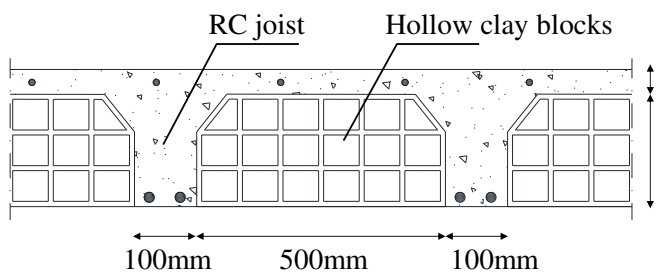

(a)

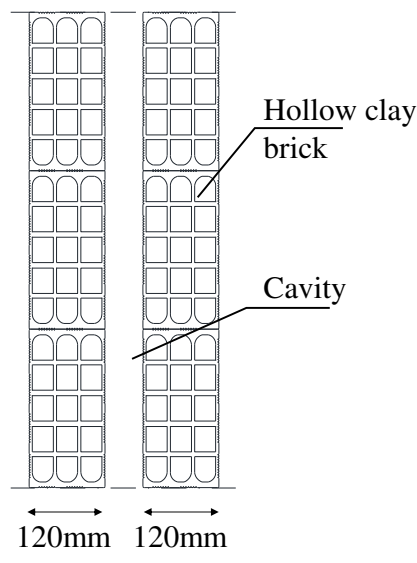

(b)

Figure 6. Details of typical slabs (a) and masonry infill walls (b) for existing RC buildings in Mediterranean area.

\subsection{Finite element modelling}

The case-study frames are modelled as 2D frames, and the VDPO-BI analysis is performed using the OpenSees software (McKenna 2010). The RC frames are modelled using force-based nonlinear beam-column elements (Spacone et al. 1996) assuming five Gauss-Lobatto integration points. Geometric nonlinearities, such as P-Delta effects, are considered in the finite element model. Beam-column joints are modelled by joining concurrent nodes, and no rigid links are adopted. The axial load variation in vertical members caused by buoyancy induces a significant reduction in columns shear capacity at each step of the analysis. This variation in shear capacity as a function of the axial load acting on the columns cannot be updated step by step during the analysis. Hence, the shear failure of members is herein evaluated on analysis results employing the capacity model suggested by the Eurocode 8 part 3 (EC8-3 2004) for existing RC members. This is to account for the effective axial load acting on structural members at each step of the analysis and to compute the actual shear capacity of columns reduced by the effect of buoyancy loads. 
The mechanical behaviour of concrete in compression is modelled with the Concrete04 material, representing the uniaxial Popovics (1973) material with degraded linear unloading/reloading stiffness according to the work of Jirsa and Karsan (1969). Given the lack of transverse reinforcement and the low axial load in columns, the confinement effect of the core concrete is herein neglected. A bilinear stress-strain envelope, Steel02 in OpenSees (Filippou 1983), is adopted for the steel longitudinal reinforcement.

A fixed restraint is adopted for the base of first story columns. The RC slab usually plays the role of diaphragm for structures, redistributing external lateral forces to structural components. In the case of tsunami loading, where the water pressure is applied directly on vertical components, the role of diaphragm on the structural performance under tsunami loads can be compromised by the blow-out failure of elevated slabs. To assess the modelling issue related to the role of the floor diaphragm in the OpenSees model, the VBPO-BI is performed for the same frame (i.e., low-rise, 3 story) with and without the inclusion of the diaphragm constraint at the first story level. The resulting lateral performance is depicted in Figure 7 in terms of base shear versus top lateral displacement (Figure 7a) and inundation depth (Figure 7b). The comparison shows that the absence of the diaphragm constraint slightly affects the lateral performance of the frame (Figure 7a) and does not modify the relationship between base shear and tsunami inundation depth (Figure 7b). For this reason, the sudden loss of diaphragm effect caused by the uplift failure of blow-out slabs during the analysis is herein neglected and the diaphragm constraint is applied at each slab level in the models even for low-out slabs.

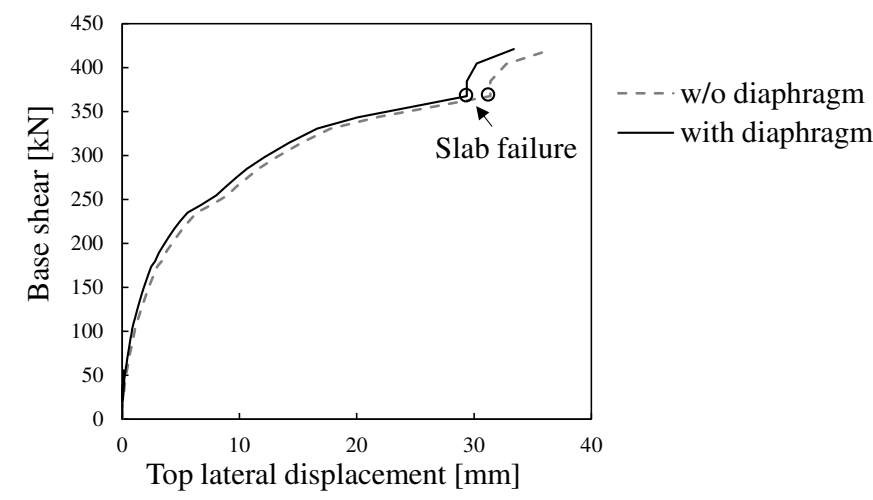

(a)

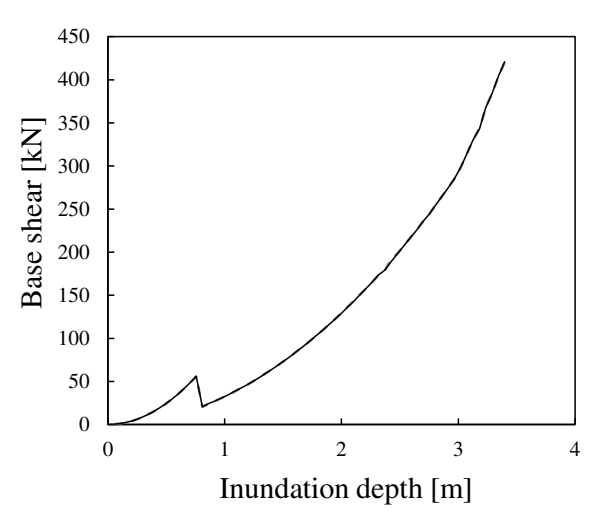

(b)

Figure 7. Effect of rigid diaphragm in the model for the low-rise case-study frame: capacity curve (a) and relation between base shear and tsunami inundation depth (b).

The non-structural components (i.e., masonry infill walls) are not included in the structural model, but their condition (undamaged or blown out) is considered during the preliminary definition of tsunami load time-histories for beams and columns to perform the VDPO-BI, as previously discussed in Section 3.2. Structural components are discretized in five nodes and load time-histories are assigned to each node of the structure. The out-of-plane capacity of masonry infill walls, 
$F_{O O P}$, and the uplift capacity of the slab, $q_{u p}$, are computed as discussed in Section 4.5. These values are used as thresholds during the generation of tsunami load time-histories. In detail, tsunami loads are preliminary computed for increasing inundation depth assuming undamaged infill walls, as shown in Figure 4a. If the $F_{O O P}$ is reached, the infill walls are considered broken away and the distribution and magnitude of loads on columns are updated to account for the smaller area over which water pressures act, as reported in Figure $4 \mathrm{~b}$. It should be noted that an equivalent uniform tsunami lateral pressure applied over the entire surface of the infill panel is computed to assess the out-of-plane failure of infill walls for increasing inundation depths. This is because the model adopted to compute the out-of-plane capacity of masonry walls is formulated for the case of uniform pressure distributed over the full height of the wall. The equivalent tsunami pressure is derived step-wise assuming an external work equal to that of the actual pressure distribution, as the infill wall experiences virtual out-of-plane displacements according to the double-arch failure mechanism ${ }^{8}$. Uplift loads on elevated slabs are also computed at each step of increasing inundation depth, and the overall uplift load is compared against $q_{u p}$. When the uplift capacity of the slab is reached, both uplift and gravity loads change to null values in the load time-histories applied to the beams to simulate the failure of blow-out slabs.

The in-plane behaviour of partitions is not herein considered due to the high variability of opening ratios observed in such walls in typical residential buildings, which can compromise the activation of struts. Dead loads are assumed to be 4 $\mathrm{kN} / \mathrm{m}^{2}$ and live loads are $1.2 \mathrm{kN} / \mathrm{m}^{2}$.

\subsection{Damage Scale for Performance Evaluation Under Tsunami Drag and Buoyancy Loads}

The HAZUS Tsunami Model Technical Guidance (FEMA 2017) provides international guidelines for the definition of damage states for buildings subjected to tsunami inundation. HAZUS damage parameters are derived under the assumption of impermeable structures (i.e., with non-breakaway exterior walls) and neglect the local failure of structural components (i.e., shear failure of columns). Furthermore, despite being for tsunami, the HAZUS damage levels are based on earthquake loading considerations and do not consider specific structural analysis for tsunami loading. Table 2 presents a summary of the HAZUS damage states as defined for RC frames. It is observed that Slight damage is not used for tsunami conditions, and only Moderate, Extensive and Complete damage are considered, and are defined based on useability and economic loss considerations. Damage levels associated to the structural damage are expressed in terms of lateral force (i.e., base-shear), with the Complete damage state associated with the achievement of the peak lateral capacity for the structure. The Moderate damage state is associated with structural yielding, and Extensive damage is defined to occur at a base shear half way between those for Moderate and Complete damage.

Table 2. HAZUS structural damage classification. 


\begin{tabular}{|c|c|c|c|c|}
\hline & SLIGHT & MODERATE & EXTENSIVE & COMPLETE \\
\hline $\begin{array}{l}\text { Global-level } \\
\text { (DUCTILE } \\
\text { MECHANISM) }\end{array}$ & N.A. & $\begin{array}{l}\text { Yield force of the } \\
\text { model }\end{array}$ & $\begin{array}{l}\text { Average of yield } \\
\text { and peak force of } \\
\text { the model }\end{array}$ & $\begin{array}{l}\text { Peak force of the } \\
\text { model }\end{array}$ \\
\hline
\end{tabular}

394 Starting from the HAZUS damage classification, mechanical damage levels herein are defined considering both ductile and brittle mechanisms at local (i.e., members level) and global structural level, as summarized in Table 3. Damage levels are defined based on considerations about the functionality and useability of the structure in the aftermath of a tsunami, along with potential direct and indirect loss. At local level, damage to both vertical members (i.e., columns) and horizonal members (i.e., slabs) are considered. Four structural damage levels are defined for the ductile damage mechanism, from Slight damage to Complete (i.e., building unusable). The ductile mechanism is associated with the development of a flexural behaviour of structural members up to the achievement of the peak base shear (i.e., global numerical instability). This usually consisting in a soft-story mechanism ${ }^{8}$, that compromise the building functionality and recovery. At memberslevel, the collapse mechanism is also related with the development of brittle mechanisms, associated to the first shear failure in first story level columns (Alam et al. 2018, Petrone et al. 2020). This represents the beginning of the loss of load bearing capacity under the long duration lateral loads induced by the tsunami flow, and is herein associated to a Complete damage level given the compromised functionality of the building after the brittle failure of columns. Given the fast activation of the soft-storey mechanism after the development of the first plastic hinge ${ }^{8}$, the HAZUS definition of Moderate and Extensive damage has been revised as follows. The Extensive damage is associated with the first structural yielding, while a Moderate damage level is considered to be reached at one-half of the yielding strain in one column. A Slight damage level is introduced to include the concrete first cracking in RC columns. Uplift failure of slabs is explicitly considered in the performance analysis. Slab flexural failure mechanism is herein associated with an extensive damage level. Although the failure blow-out slabs does not compromise the stability of a building, this memberlevel failure compromises the functionality of the entire building in the aftermath of a tsunami, with significant consequences on direct and indirect costs. Given the uniform distribution of uplift loads on slabs, the punching shear failure of slabs is not herein considered as a possible failure mechanism under tsunami-induced uplift loads.

Table 3. Proposed structural damage scale and EDP threshold values. 


\begin{tabular}{|c|c|c|c|c|}
\hline & SLIGHT & MODERATE & EXTENSIVE & COMPLETE \\
\hline $\begin{array}{l}\text { Vertical members-level } \\
\text { (DUCTILE } \\
\text { MECHANISM) }\end{array}$ & $\begin{array}{l}\text { First } \\
\text { achievement } \\
\text { in any } \\
\text { vertical } \\
\text { member of } \\
\text { concrete } \\
\text { cracking } \\
\left(M_{c r}\right)\end{array}$ & $\begin{array}{l}\text { First achievement } \\
\text { in any vertical } \\
\text { member of } 1 / 2 \\
\text { steel yield strain } \\
\left(1 / 2 \varepsilon_{y}\right) \text { in the } \\
\text { longitudinal steel }\end{array}$ & $\begin{array}{l}\text { First achievement } \\
\text { in any vertical } \\
\text { member of steel } \\
\text { yield strain }\left(\varepsilon_{\mathrm{y}}\right) \text { in } \\
\text { the longitudinal } \\
\text { steel }\end{array}$ & N.A. \\
\hline $\begin{array}{l}\text { Global-level } \\
\text { (DUCTILE } \\
\text { MECHANISM) }\end{array}$ & N.A. & N.A. & N.A. & $\begin{array}{l}\text { Peak base shear } \\
\left(V_{b}\right)\end{array}$ \\
\hline $\begin{array}{l}\text { Vertical members-level } \\
\text { (BRITTLE } \\
\text { MECHANISM) }\end{array}$ & N.A. & N.A. & N.A. & $\begin{array}{l}\text { First achievement } \\
\text { in any vertical } \\
\text { member of shear } \\
\text { capacity }\left(V_{R}\right)\end{array}$ \\
\hline $\begin{array}{l}\text { Horizontal members- } \\
\text { level }\end{array}$ & N.A. & N.A. & $\begin{array}{l}\text { First achievement } \\
\text { of slab flexural } \\
\text { capacity }\left(q_{u p}\right)\end{array}$ & N.A. \\
\hline
\end{tabular}

418 The performance and fragility of the structure against tsunami-induced lateral and vertical loads is assessed through the 419 VDPO-BI analysis as presented in Section 3.2. Local and global Engineering Demand Parameters (EDP) are selected to 420 monitor the structural response. Local EDPs consist in longitudinal steel strains and bending moments at critical sections 421 of first storey level columns (i.e., top and bottom cross-sections), and shear forces acting on the first storey level columns. 422 Overall uplift loads acting on elevated slabs are also considered as EDP for the damage mechanism associated to the 423 blow-out slabs. The base shear $(F)$ is assumed as global EDP to evaluate the structural capacity at complete damage. EDP 424 thresholds for the achievement of each damage level (i.e., $\mathrm{EDP}_{\mathrm{DL}}$ ) are also summarized in Table 3 (i.e., $M_{c r}$ is the cracking 425 bending moment, $\varepsilon_{\mathrm{y}}$ is the steel yielding strain). The columns shear capacity, $V_{R}$, is computed according to EC8-3 ${ }^{27}$ 
provisions for existing structures. The flexural capacity of slabs against uplift loads strictly depends on the slab typology considered. Details on slabs capacity estimation are reported in Section 4.5 for the case-study frames selected for this study.

\subsection{Tsunami fragility including buoyancy loads}

Tsunami fragility assessment is performed through numerical analyses to assess the effect of buoyancy induced loads on the probability to exceed a certain structural damage level, defined in Table 2, as a function of the tsunami intensity. The tsunami inundation depth, $H_{w}$, is here adopted as a scalar intensity measure (IM) for the tsunami hazard, even though several studies identified other scalar and vector-valued tsunami parameters suitable to determine fragility curves (Park et al.2017, Charvet et al. 2017). However, the water depth is commonly the most adopted IM for empirical tsunami fragility functions, being easily monitored during post-tsunami in-situ inspections. Furthermore, given the relation between flow depth, Froude number and flow velocity (i.e., $F r=u / \sqrt{g H_{w}}$, with $F r$ kept constant during the VDPO$\mathrm{BI})$, the scalar intensity measure $H_{w}$ can be easily transformed in a vector-valued intensity measure $\mathbf{I M}=\left[H_{w}, u\right]$. The fragility curves are then modelled as a cumulative lognormal distribution of observed data from numerical analyses, with mean $\left(\mu_{D S}\right)$ and logarithmic standard deviation $\left(\beta_{D S}\right)$ computed as mean and standard deviation of the actual distribution of scalar IMs.

\subsection{Characterization of uncertainties}

In the probabilistic framework adopted to develop single-building tsunami fragility curves, uncertainties are taken into account for both capacity and demand parameters. It should be noted that the scope of the paper is not to provide fragility functions for RC buildings, but instead to address the effects of modelling buoyancy loads and blow-out slabs on the fragility of frames. Uncertainties about the geometry of case-study buildings are neglected in the single-building fragility assessment. Uncertainties on capacity are related to material properties to be adopted for structural and non-structural components, as well as capacity models to be used to assess threshold values for the infill walls out-of-plane capacity and the slabs uplift failure. Conversely, uncertainties on tsunami demand are mainly related to the Froude number characterizing the tsunami flow at the building location. Uncertainties on demand also involve the load combination to be used during the performance assessment. According to ASCE 7-16 provisions, two load combinations should be considered for tsunami design, where $D$ are dead loads, $L$ are live loads, and $T_{s u}$ are tsunami lateral and buoyancy loads:

COMBO 1) 0.9D + Tsu

COMBO 2) $1.2 \mathrm{D}+0.5 \mathrm{~L}+\mathrm{Tsu}$

Uncertain parameters are considered as independent random variables. The Latin Hypercube algorithm and Monte Carlo simulation are adopted to generate a sample of $10^{3}$ random combinations of the selected variables, each corresponding to a building possible realization. 
The fragility function for a specific damage level is then computed on the sample of $10^{3}$ random combinations as $P[$ IM $<$ $\left.\mathrm{IM} \mid \mathrm{EDP}=\mathrm{EDP} \mathrm{DL}_{\mathrm{DL}}\right]$

A set of aleatory variables with normal or uniform distribution are defined to explicitly account for uncertainties related to capacity and external demand, as summarized in Table 4. For variables with a uniform distribution, the range of variability is reported; conversely, in the case of normally distributed variables, both mean and $\mathrm{CoV}$ (in brackets) are indicated.

There is little consensus about the appropriate characterization of uncertainties related to material properties in existing RC buildings. The present study adopts statistics from relevant studies performed in the Mediterranean region that derived fragility functions of existing buildings and building stocks (Borzi et al. 2008, Parisi and Sabella 2017). Mean values of mechanical properties are considered for the performance assessment of the RC frames. To obtain mean values, the concrete characteristic compressive strength is multiplied by a factor $\gamma_{c}=1.1$, and the steel strength is multiplied by $\gamma_{s}=1.5$ (Priestley et al. 1996). To account for uncertainties in steel and concrete mechanical properties for the single-building fragility assessment, yielding and compressive strength are considered as normally distributed random variables with a $\mathrm{CoV}=10 \%$ (Borzi et al. 2008). Statistics for the out-of-plane capacity of typical exterior infill walls, $F_{O O P}$, are derived using the double-arch analytical model reported in Del Zoppo et al. (2021a) through Monte Carlo simulation on $10^{3}$ samples, assuming as random variables the masonry mean compressive strength of $1.5 \mathrm{MPa}(\mathrm{CoV} 14 \%)$ and the masonry elastic modulus of $1.8 \mathrm{GPa}(\mathrm{CoV} 14 \%)$ (Parisi and Sabella 2017). Given the internal cavity of the typical infill walls configuration considered for the case-study frames, and only the thickness of the outer layer of bricks is considered for computing the infill walls capacity (i.e., $120 \mathrm{~mm}$ ). This implies a very weak capacity of infill walls in the out-of-plane direction. Uncertainties on the uplift capacity of slabs, $q_{u p}$, are also considered within the fragility assessment framework. The flexural capacity of the RC slabs is conservatively computed using sectional analysis as the flexural capacity at first cracking, $M_{\text {cracking,slab }}$, given the lack of tensile reinforcement at the mid-span under negative bending moment:

$$
M_{\text {cracking, slab }}=f_{t} I / y_{G}
$$

480 where $f_{t}$ is the concrete tensile strength, computed as $0.3 f_{c}^{2 / 3}$ as per Eurocode 2 - Part 1 (2004), with $f_{c}$ the concrete 481 compressive strength, $I$ the inertia of the slab cross-section and $y_{G}$ the distance of the upper concrete fibre from the centroid 482 of the section. The uplift load capacity is then calculated from:

$q_{u p}=k M_{\text {cracking,slab }} / L^{2}$

484 where $L$ is the span of the slab (i.e., equal to $5 \mathrm{~m}$ ) and $k$ a coefficient depending on bending moment diagram. Statistics 485 for $q_{u p}$ are computed running a Monte Carlo simulation on $10^{3}$ samples, assuming a mean concrete compressive strength $f_{c}$ of $22 \mathrm{MPa}(\mathrm{CoV} 10 \%)$ and $k$ ranging between 9 and 13, assuming a uniform distribution. 
Tsunami lateral loads are computed assuming a dense urban environment, $B / w=0.6$ (i.e., $C_{D}=4.7, \lambda_{s}=2.0, F r_{-} c=0.32$ ), and a Froude number ranging between 0.7 and 2.0 for this application. Although debris accumulation should be considered for the tsunami fragility assessment, for the present study, a negligible damming debris accumulation at the site of the structure is assumed (i.e., $C_{c}=0$ ). This is deemed acceptable as the focus of this paper is to assess the influence of vertical loads on structural performance, and significant lateral loads are already considered to be attracted to the structure due to the presence of infill walls. Given this assumption, the case study buildings can be considered as representative of buildings directly facing the shoreline (i.e., first row), and away from significant sources of damming debris. It should be noted that such structures are also exposed to the impact loads from floating debris (i.e., boats) (Ghobarah et al. 2006). fragility curves.

Table 4. Uncertainties for fragility assessment of case-study frames.

\begin{tabular}{|c|c|c|c|}
\hline & Variable & Distribution & Mean (CoV) or range of variation \\
\hline \multirow{4}{*}{ 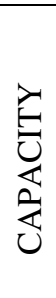 } & $f_{s}$ & Normal & $570 \mathrm{MPa}(10 \%)$ \\
\hline & $f_{c}$ & Normal & $22 \mathrm{MPa}(10 \%)$ \\
\hline & $F_{O O P}$ & Normal & $26.3 \mathrm{kN} \mathrm{(53 \% )}$ \\
\hline & $q_{u p}$ & Normal & $5.5 \mathrm{kN} / \mathrm{m}^{2}(11 \%)$ \\
\hline \multirow{2}{*}{ 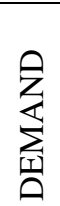 } & $F r$ & Uniform & $0.7-2.0$ \\
\hline & $\begin{array}{c}\text { Load } \\
\text { combination }\end{array}$ & Random & COMBO 1 or $C O M B O 2$ \\
\hline
\end{tabular}

\section{Results and Discussion}

The effects of buoyancy-induced loads and blow-out slabs on the damage mechanisms, performance curves and fragility curves of the three case-study frames are herein illustrated and discussed. Considerations are also made relatively to the consequent effect on tsunami vulnerability and loss estimation.

\subsection{Performance assessment}

Damage mechanisms evolution and performance curves derived with the VDPO-BI analysis are first illustrated for the three case-study frames under the three scenarios reported in Table 1: (scenario $i$ ) uplift loads on slabs are neglected during the analysis; (scenario ii) uplift loads are considered but the uplift failure of the slab is neglected (i.e., non-blowout slabs); (scenario iii) uplift loads and blow-out slabs are both considered. 
The case-study frames are analysed assuming mean values for the random variables related to the capacity. The analyses are performed assuming the Load Combination 1 (Eq. 6) and a Froude number of 0.7, which is the lower bound of the selected range of investigation (Table 4).

\subsubsection{Damage Mechanisms Evolution}

Figure 8 shows the damage mechanisms evolution for the three case-study frames with indicated the occurrence of the different EDPs used to define the damage scale in Table 3 as a function of the inundation depth. The Figure is derived for all the scenarios herein investigated. The Extensive damage associated with the slab failure is computed only for scenario iii, where uplift loads and blow-out slabs are considered. The damage evolution for $F r=0.7$ shows that the uplift failure of blow-out slabs is the first extensive damage level achieved by the mid and high-rise case-study frames, when blow-out slabs are considered (e.g., scenario iii), directly followed by the brittle mechanism of vertical members, see Figures $8 \mathrm{~b}$ and Figures 8c. In these cases, the brittle mechanism is affected by uplift loads acting on non-blow-out slabs that cause a slight reduction of shear capacity (scenario ii). The brittle collapse of vertical elements in the structure precedes the occurrence of extensive ductile damage states, as defined in the damage scale herein adopted. This result is in line with other studies in literature. Indeed, previous numerical studies revealed that the shear failure of seaward columns is a predominant collapse mechanism for frame structures subjected to tsunami, preventing the development of plastic deformations in columns (Alam et al. 2018).

Conversely, for the low-rise case-study frame, the ductile complete damage mechanism is predominant. The brittle mechanism is not achieved for the low-rise case-study frame under $F r=0.7$, see Figure 8a. However, it is worth noting that the assumption about the Froude number affects significantly the damage mechanisms evolution, as further discussed in Section 5.2. The extensive damage associated with blow-out slabs is achieved at almost same inundation depth values of the extensive damage for ductile mechanisms.

The ductile performance of the mid and high-rise case-study frames is computed assuming that the premature brittle failure mechanism is avoided. This is useful to show the inclusion of buoyancy loads in the structural analysis and their influence on the structural response, without consideration of precipitation of structural failure through brittle mechanisms. Figure 8 shows that the effect of uplift loads is visible for slight to extensive ductile damage states, whilst it is negligible at complete damage for the three case-study frames. More specifically, uplift loads anticipate the occurrence of EDP thresholds for the ductile mechanisms if non-blow-out slabs are assumed (scenario ii). To further investigate the effect of buoyancy-induced uplift loads on ductile mechanisms, the ductile performance of the three case- 


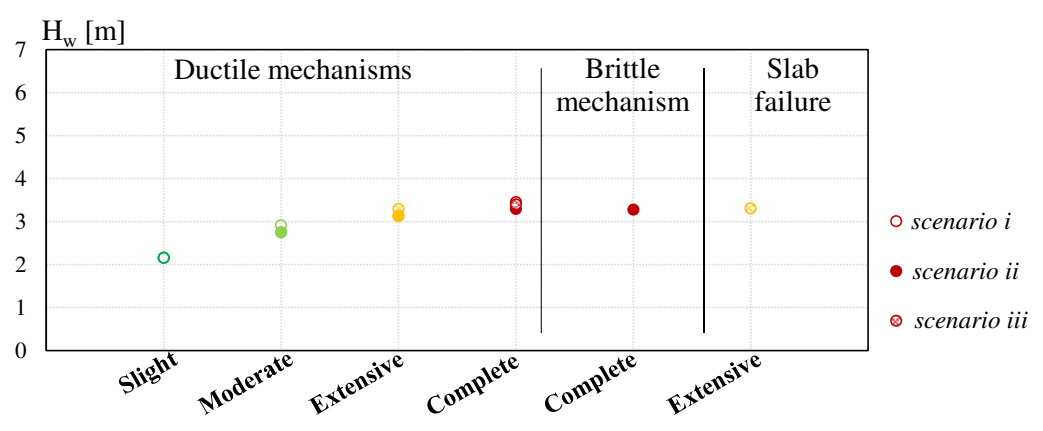

(a)

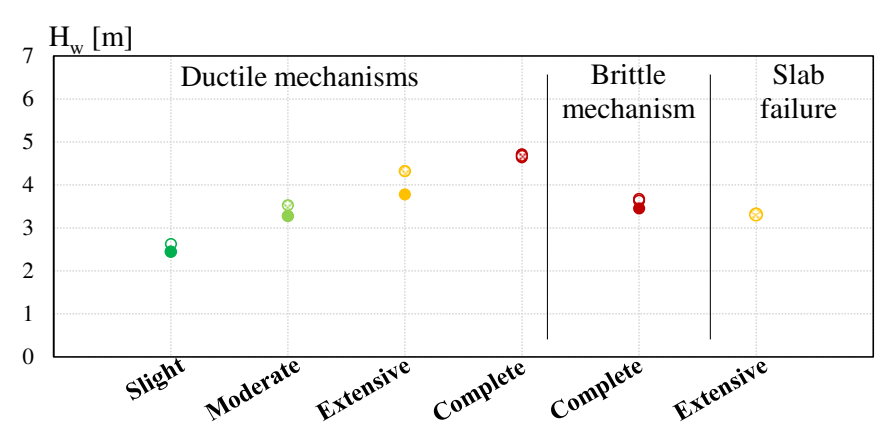

(b)

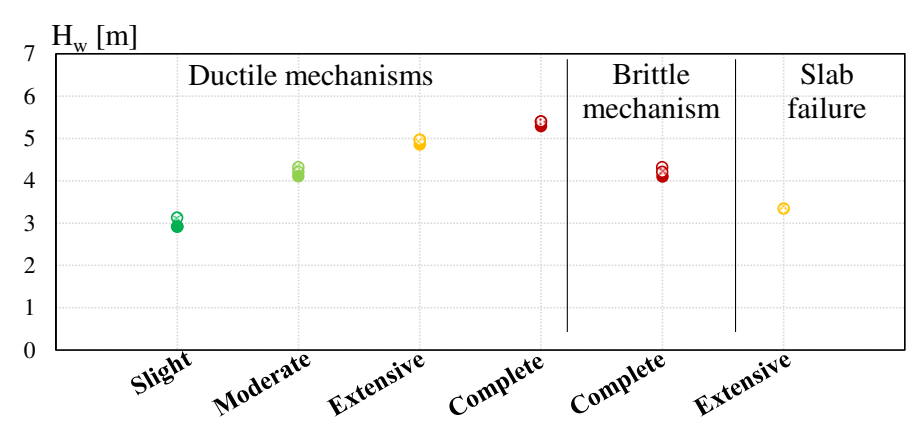

(c)

Figure 8. Damage mechanisms for a Froude number of 0.7: low (a), mid (b) and high-rise (c) case-study frames.

\subsubsection{Ductile Performance}

542 Figure 9 shows the ductile performance curves in terms of tsunami inundation depth, $H_{w}$, versus top horizontal 543 displacement for the mid-rise (i.e., 6 storey) RC frame under the three considered scenarios (Table 1). EDP thresholds 544 associated with the ductile damage levels are also indicated in Figure 9 along with the out-of-plane failure of exterior infill walls. Dips in the ductile performance curves for the three scenarios are observed to be associated with the out-ofplane failure of breakaway infill walls. Indeed, the infill walls failure causes a sudden reduction of lateral loads acting on the seaward column and a redistribution of loads on interior columns; this induces an elastic reduction of lateral 

reached after the failure of second story breakaway infill walls. Conversely, in scenario $i$, slight to extensive damage levels are achieved for a lower value of inundation depth with respect to scenario $i$ due to the effect of buoyancy-induced uplift loads on non-blow-out slabs. The uplift loads on slabs are seen to significantly reduce the axial load in first story columns and the related bending moment capacity. The global ductile failure in scenario ii is slightly affected by buoyancy, due to the failure of second storey infill walls that causes a relieve in vertical loads acting on non blow-out slabs. Under scenario iii, the uplift failure of the blow-out slabs at first floor is reached before the failure of second story infill walls and directly after the achievement of the moderate ductile damage level. In scenario iii, after the failure of blow-out slabs the performance curve shows a similar trend to scenario $i$, due to the structural relieve deriving from the absence of buoyancy loads.

Scenario $i$

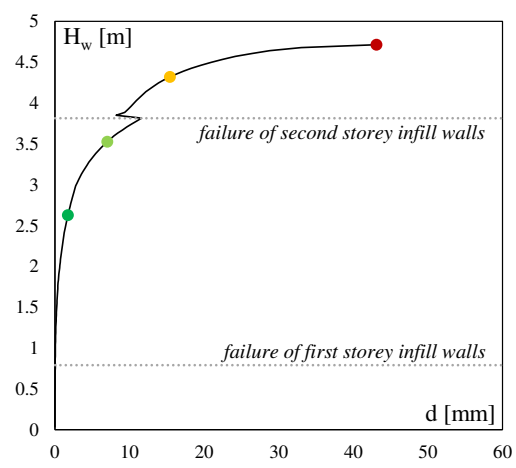

Scenario $i$

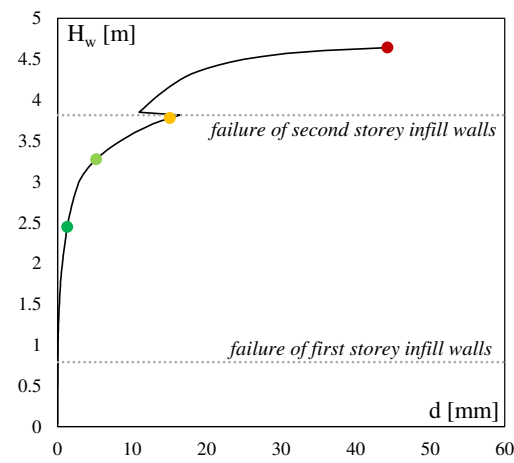

\section{Scenario iii}

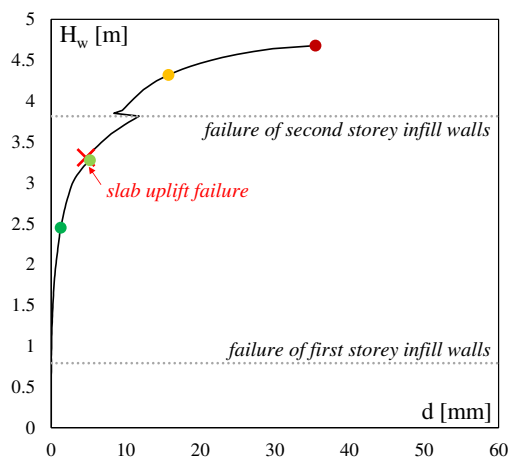

Figure 9. Ductile performance curves for the mid-rise frame under scenarios $i$, ii and iii for $F r=0.7$.

Ductile capacity and performance curves for the three case-study frames under the considered scenarios are compared in Figure 10. The considerations derived for the mid-rise frame also apply to the low and high-rise frames. However, for the low-rise frame, the global ductile failure mechanism is reached before the failure of second story infill walls under the three scenarios, given the lower flexural capacity of first story columns.

In general, it is observed that before the uplift failure of elevated slabs, the ductile performance curves are similar for all frames under scenarios $i i$ and $i i i$. After the slab uplift failure, the ductile performance curve for scenario iii tends to follow the one of scenario $i$, since uplift loads are no longer acting on the structure. The failure of slabs does not affect the maximum lateral capacity of the frames (if shear effects are not considered). Indeed, after the failure of the first story slab, the inundation depth is further increased up to the achievement of the peak base shear. In this case, the maximum lateral capacity of frames with blow-out slabs (scenario iii) is almost the same as is achieved for frames when uplift loads are neglected (scenario $i$ ). 
The curves also show that buoyancy loads lead to a slight reduction of the overall lateral capacity for the case-study frames in the case of non blow-out slabs (scenario ii). This is because, in the case of non blow-out slabs, the uplift loads acting on the slabs significantly increases during the incremental analysis (see Figure 3a) up to the out-of-plane failure of infill walls. For the low-rise frames, the maximum lateral capacity for scenario $i i$ is achieved before the out-of-plane failure of second story infill walls. Conversely, in the mid and high-rise frame, the failure of second story infill walls is reached for scenario $i i$, causing a significant reduction of uplift loads on first story slab, see Figure $3 \mathrm{~b}$. The reduction of uplift loads in scenario $i i$ allows the frames to achieve the same maximum lateral capacity as under scenarios $i$ and $i i$.
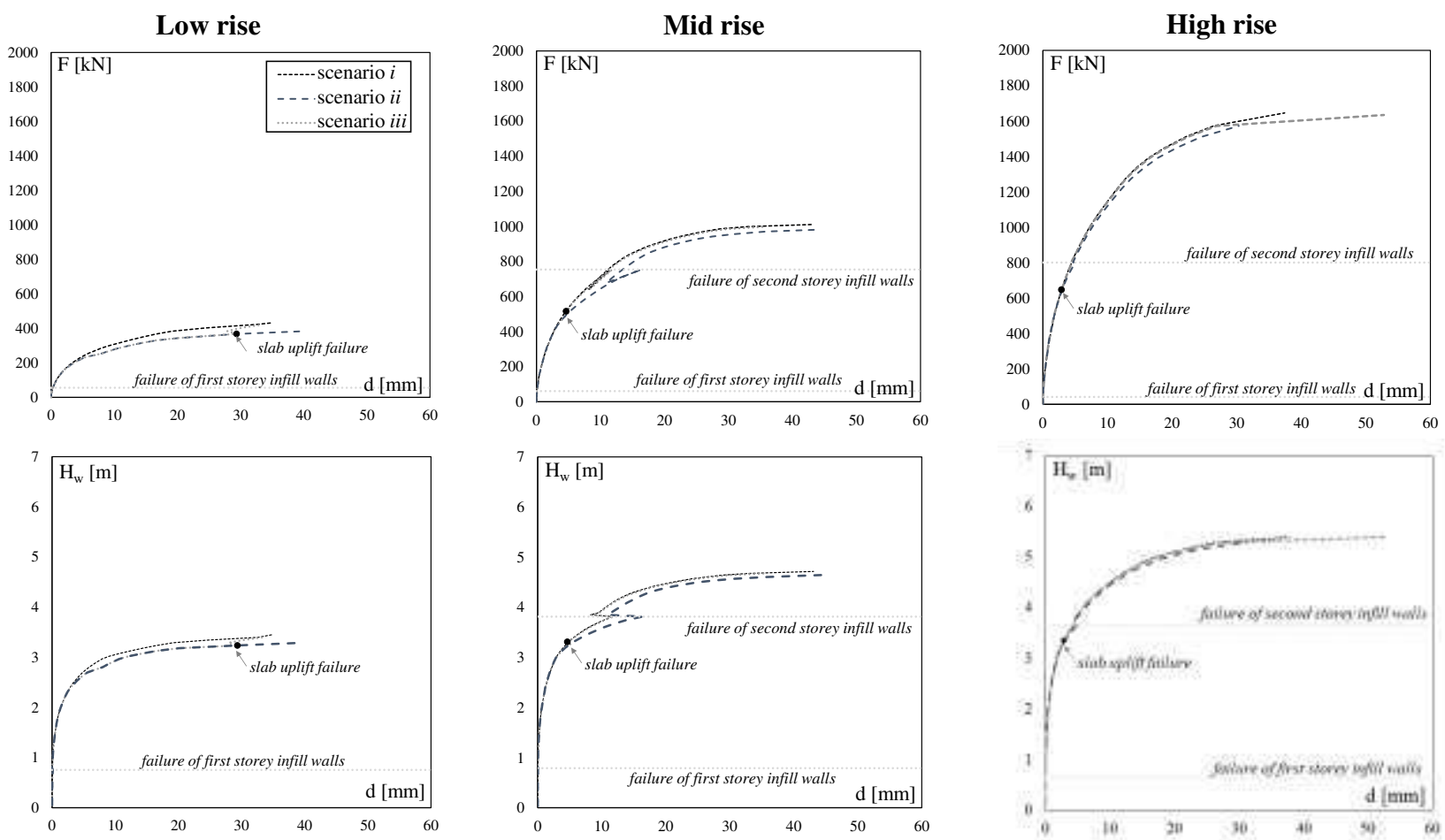

Figure 10. Ductile capacity curves and performance curves for the case-study frames under the three scenarios investigated for $F r=0.7$.

The axial load $(P)$ variation in first story exterior and interior columns due to buoyancy loads during the VDPO-BI is illustrated in Figure 11a and b for low and high-rise frames, respectively. The plots show there is a significant reduction of axial loads caused by the uplift loads on first story slab for increasing inundation depth. When failure of blow-out slabs occurs, this induces a sudden relief for the columns, reducing the effect of internal buoyancy. Overall, the reduction in axial load due to buoyancy is obviously more significant for low-rise frame rather than high-rise frames due to the lower dead loads, leading to a consequent reduction of flexural capacity recognized on performance curves in Figure 10 


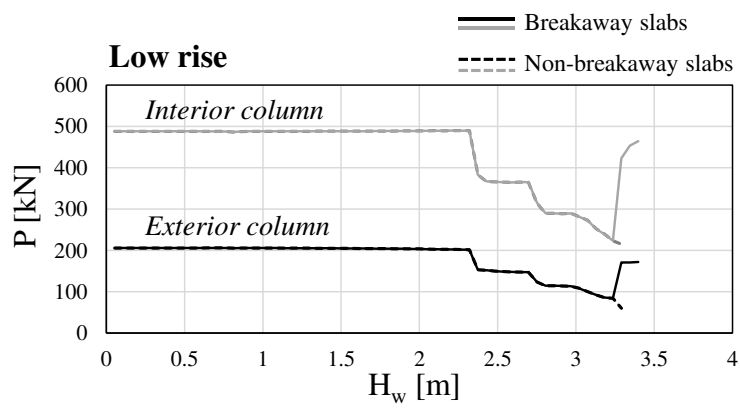

(a)

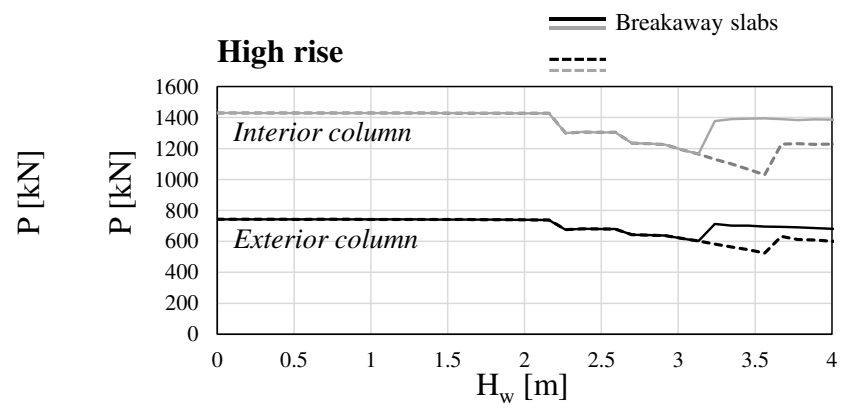

(b)

Figure 11. Axial load variation in columns as a function of increasing inundation depth for low-rise (a) and high-rise (b) frames for $\mathrm{Fr}=0.7$.

Maximum interstory drift ratios (MIDR) at the last step (i.e., numerical instability) of the VDPO-BI analysis are also reported for the case-study buildings in Figure 12 as a function of the building height (e.g., Figure 12a for the low rise frame, Figure 12b for the mid rise frame, Figure 12c for the high rise frame). The plots show that the three frames develop the same flexural behaviour, with high concentration of lateral drifts at first story level. This is compatible with the development of a soft-story mechanism at first story of the frames during the tsunami inundation.

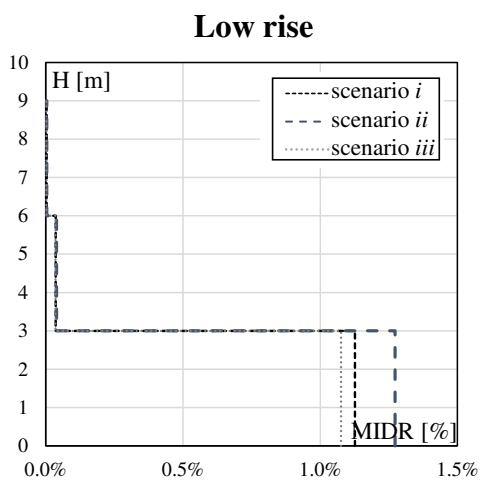

(a)
Mid rise

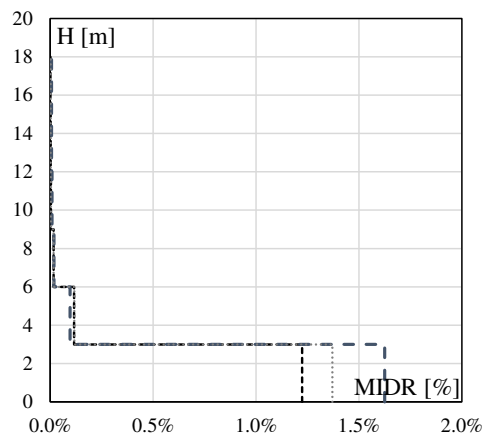

(b)
High rise

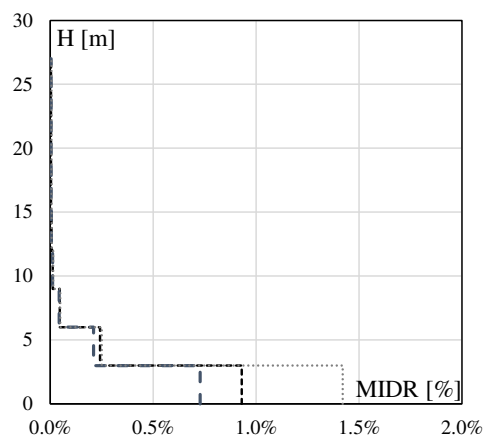

(c)

Figure 12. Maximum interstory drift ratios at numerical instability for the case-study frames for $\mathrm{Fr}=0.7$.

\subsection{Fragility curves}

A set of analytical tsunami fragility curves is derived for each case-study frame under the three selected scenarios, for the damage levels scale presented in Table 2. Figure 13 shows the fragility functions with respect to the observed IMs derived for the three case-study frames under scenario iii (i.e., with buoyancy loads and blow-out slabs), that allows for a complete damage assessment for the structures. Aggregated datapoints of observed IMs are also shown for graphical reference in 
Figure 13 (the dimension of datapoints is a function of the amount of data for each discrete interval). Fragility curves are presented separately for ductile and brittle damage mechanisms associated to vertical members and for damage related to horizontal members. It should be noted that the EDP threshold associated with damage to horizontal members is not always reached during the VDPO-BI analysis. Indeed, in several cases the global numerical instability of the model is reached before the uplift failure of the slab is achieved, as further discussed in the next. Hence, fragility curves at the horizontal members-level reported in Figure 13 are not computed for the full sample but only for those realizations in the sample that developed the uplift failure of slab before the global numerical instability. The lognormal fragility curves in Figure 13 show a good agreement with the observed numerical data at all damage levels herein investigated.

It is also noted that the fragility curves associated with the damage to horizontal components (i.e., blow-out slabs) is quite steep, indicating a very low variability with respect to the uncertainties selected for the study. This is because the failure of the slab mainly depends on the slabs' capacity and on the volume of enclosed spaces over the slab that generates the internal buoyancy (which is a function of the inundation depth and the out-of-plane capacity of second story infill walls). Both slabs and infill walls capacity are assumed the same for the three case-study frames. Hence, the slabs uplift failure is achieved at almost same inundation depths for all the frame configurations.

Ductile mechanisms -

Vertical members-level and Global-

level
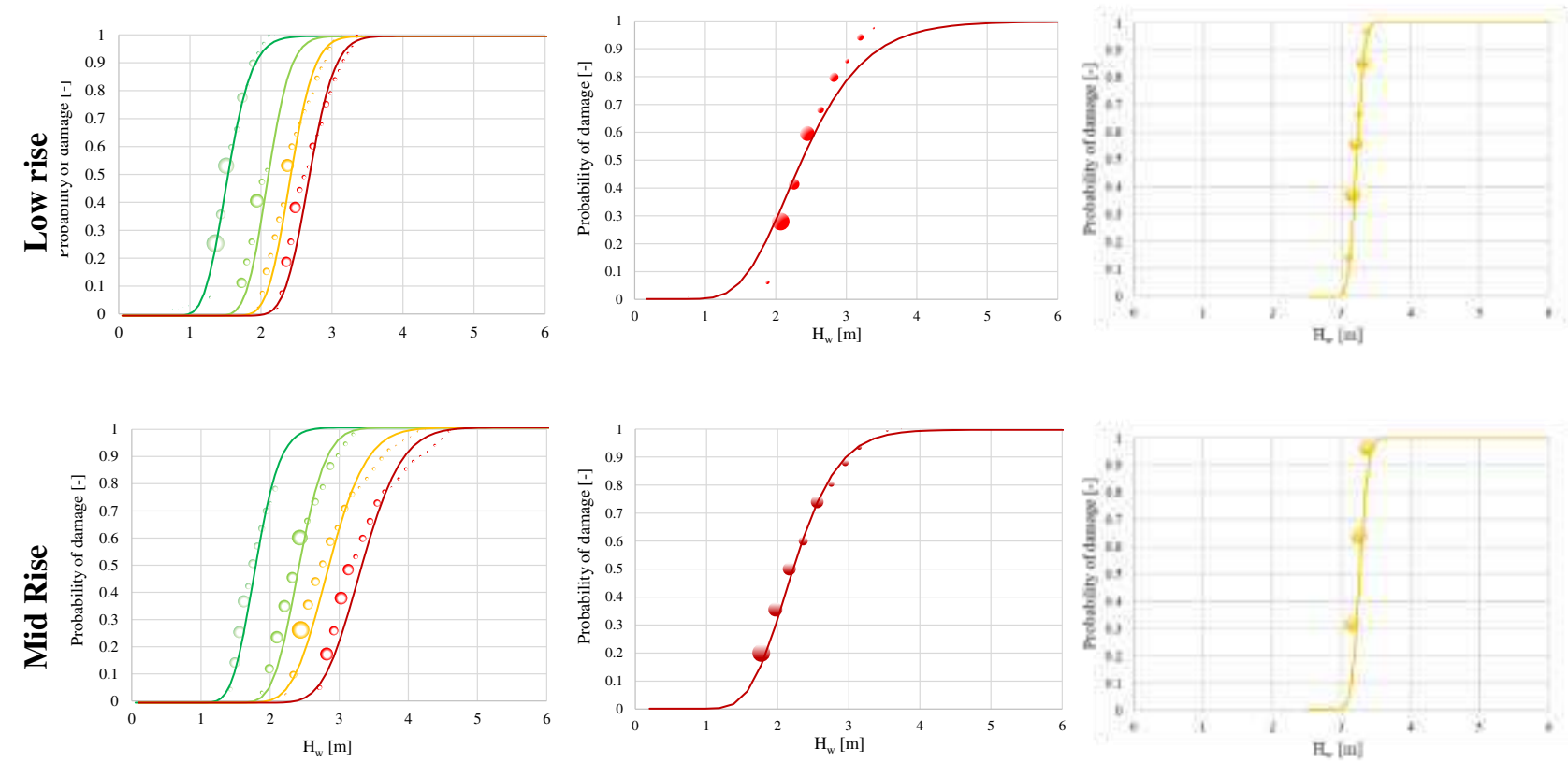

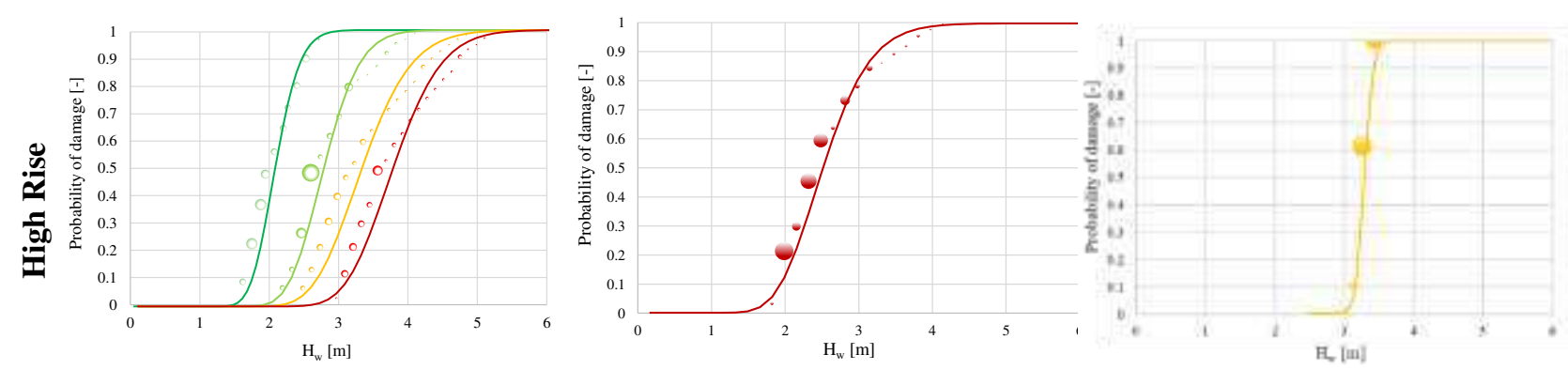

Figure 13. Fragility curves for scenario iii (i.e., with uplift loads and blow-out slabs). Datapoints dimension refers to the amount of data in each discrete interval of IM.

For the three case-study frames, the predominant complete damage mechanism is associated with the brittle shear failure of columns. Indeed, this is the first complete damage mechanism reached for almost all building realizations in the sample. In 30 low-rise realizations, 41 mid-rise realizations and 137 high-rise realizations (rate of occurrence $3.0 \%, 4.1 \%$ and $13.7 \%$, respectively) the failure of the slabs is achieved before the brittle mechanism, as previously found during the single-building performance assessment in Figure 8b,c. It is also observed for the low-rise case-study frames that the brittle mechanism is not achieved for 23 realizations of the sample (rate of occurrence $2.3 \%$ ), characterized by a Froude number lower than 0.77, as found in the performance assessment shown in Figure 8a for Fr=0.7.

The uplift failure of slabs is not reached for all the building realizations in the samples used to derive the fragility curves. Some realizations are seen to reach numerical instability (i.e., complete damage for ductile mechanisms) before the uplift failure of first story slabs is achieved. The rate of occurrence of slab uplift failure with respect to complete ductile damage is shown in Figure 14 for the sample of case-study frames as a function of the Froude number and the uplift capacity of the slab. For the low-rise frame, slab uplift failure is achieved before the global numerical instability (i.e., global level, ductile failure) in only $7.5 \%$ of investigated cases, see Figure 14a. Hence, the predominant damage mechanisms for the low-rise frame are associated with the ductile mechanism if brittle shear failures are prevented. This strongly depends on the magnitude of tsunami lateral load, expressed by means of the Froude number, rather than from the slab capacity. Indeed, for Froude number greater than 0.9 the global instability is always achieved before the slab failure.

A higher rate of occurrence of slabs uplift failure is observed for mid (46.5\%) and high-rise frames (77.7\%), given the greater dimension of columns at the first story level which provides a larger lateral capacity with respect to the low-rise frame. For such case-study frames, the tsunami Froude number governs the occurrence of interior slabs uplift failures, as shown in Figure 14b and c. 


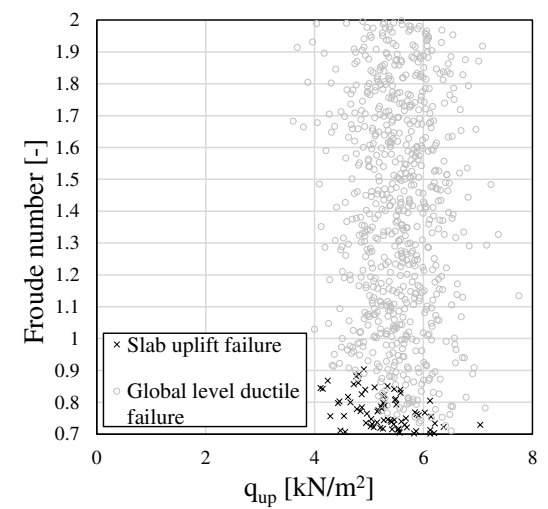

(a)

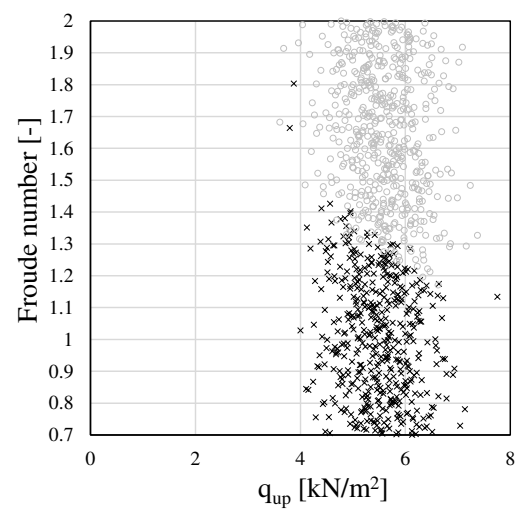

(b)

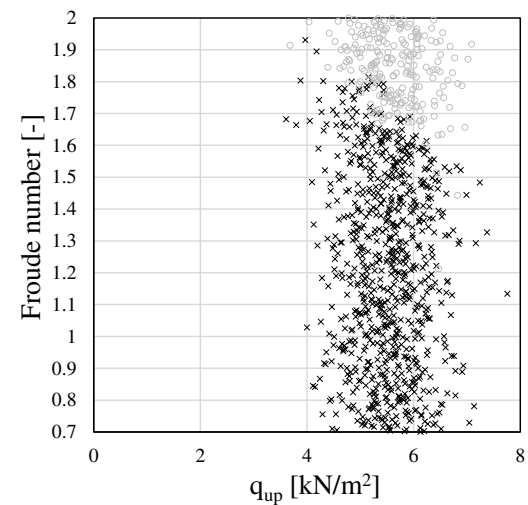

(c)

Figure 14. Occurrence of first story slab uplift failure for low (a), mid (b) and high-rise (c) case-study frames.

\subsubsection{Effect of buoyancy loads on tsunami fragility curves}

The effect of buoyancy-induced loads on fragility curves is investigated for both ductile and brittle mechanisms. To investigate the effect of buoyancy on the fragility for ductile mechanisms, fragility curves are first derived for the lowrise frame for the three scenarios in Table 1 and are compared in Figure 15. The Figure shows that buoyancy-induced uplift loads only slightly affect the Slight to Moderate damage levels for the ductile mechanism. This is because the inundation depth associated with these damage levels is usually lower than the soffit of first story slab, and no uplift loads are acting on the elevated slabs. Conversely, for Extensive to Compete ductile damage levels, tsunami uplift loads are acting on the slabs due to buoyancy. The fragility associated to these damage levels for the low-rise frame under scenarios $i i$ and $i i i$ is slightly increased (i.e., reduction in median and logarithmic standard deviation), with respect to scenario $i$ due to the effect of uplift loads on slabs. The difference in ductile fragility curves between scenarios $i i$ and iii is almost negligible, given the low rate of occurrence of slabs uplift failure for the case-study frame. Indeed, if the uplift failure of blow-out slabs is not reached, the overall structural performance under scenario $i i$ and $i i i$ is the same. 


\section{Low Rise - Ductile mechanism}
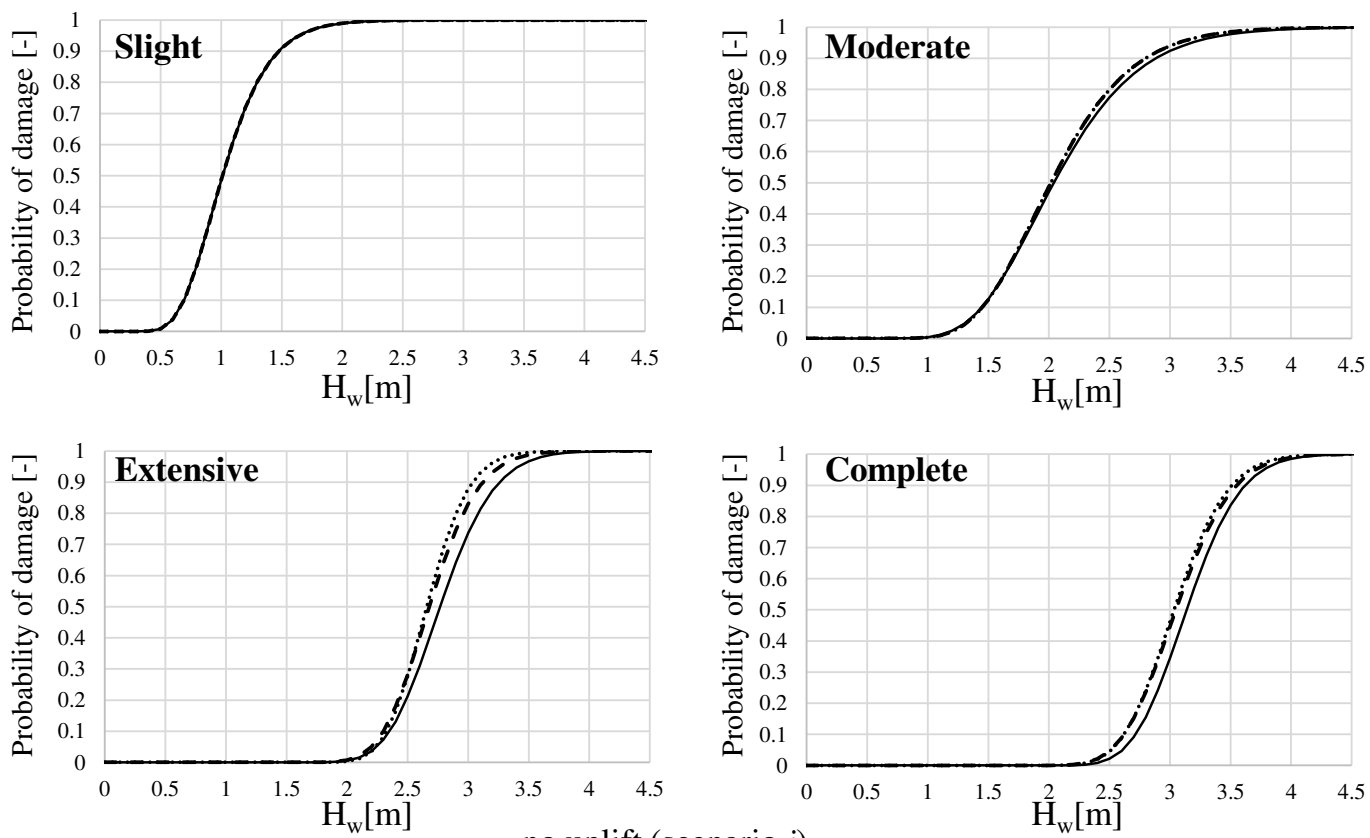

- - - uplift + non blow-out slab (scenario $i i)$ uplift + blow-out slab (scenario iii)

Figure 15. Effect of buoyancy loads on fragility curves for ductile mechanisms on the low-rise case-study frame.

The full set of mean and logarithmic standard deviation $\left(\mu_{D S}\right.$ and $\left.\beta_{D S}\right)$ of fragility curves associated with the ductile damage mechanisms for all three case study frames are summarized in Figure 16. The comparison of mean (Figure 16a) and logarithmic standard deviations (Figure 16b) of fragility curves derived for the mid-rise frame shows a slight increase in fragility from Slight to Complete damage levels for scenario $i i$ with respect to scenario $i$, where uplift loads are neglected. is recognized for scenario $i i$, where non blow-out slabs are assumed.
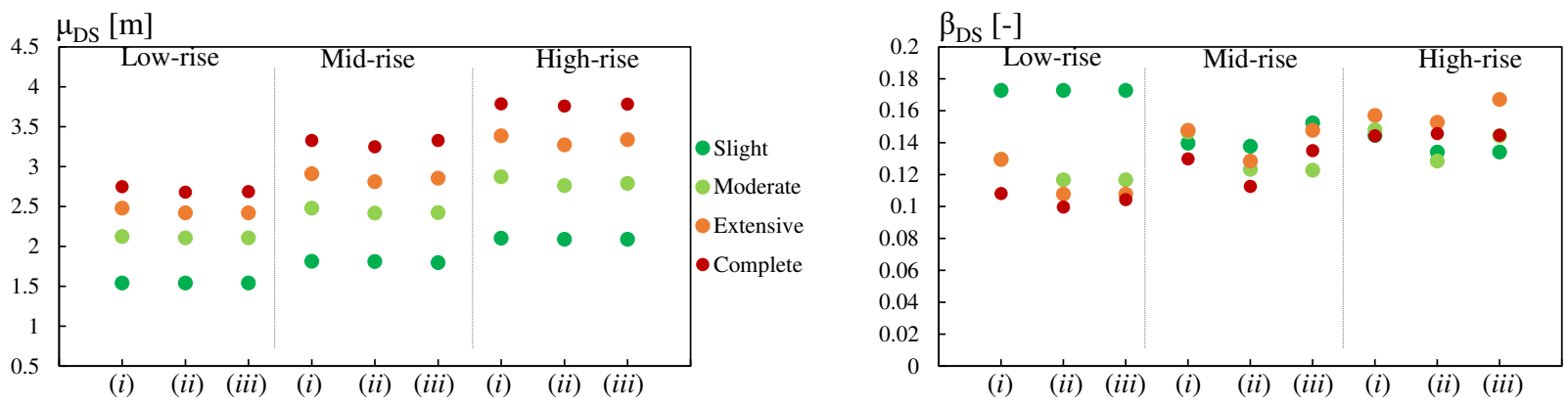
Figure 16. Mean (a) and logarithmic standard deviation (b) of fragility curves for ductile mechanisms for the case-study

Fragility curves associated with brittle damage mechanism for the three scenarios are first investigated for the high-rise case-study frame, for which a higher effect of uplift loads on such failure mechanism with respect to the low and midrise frames has been observed (see Figure 8). However, fragility curves in Figure 17 shows that the effect of uplift loads on fragility for the brittle mechanism is almost negligible for the investigated case-study frame. This because the brittle mechanism is usually reached for inundation depths lower than the first story slab soffit, when null or negligible buoyancy loads develop below the slab. Indeed, only for a very limited number of cases in the sample investigated herein the shear failure of slabs is preceded by the uplift failure of blow-out slabs, as discussed in Section 4.2. The same observations made for the high-rise frame also apply to the low and mid-rise frames, and data are not herein reported for the sake of brevity.

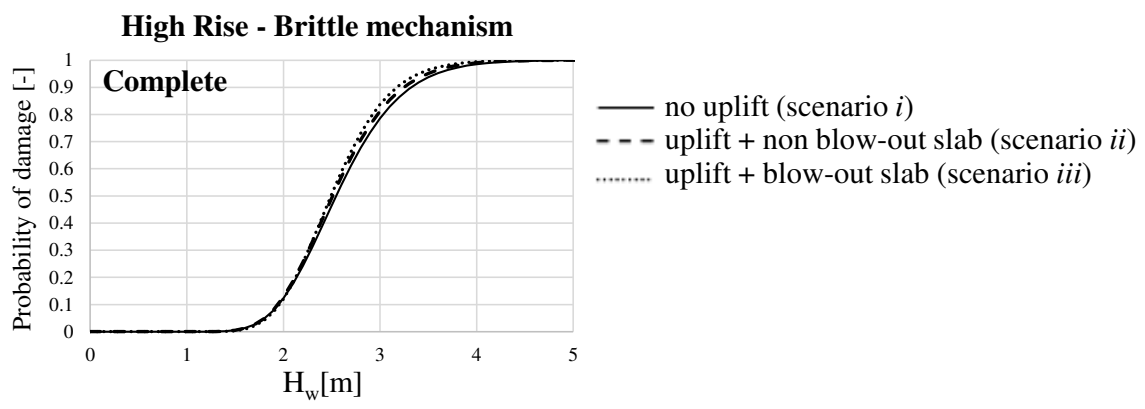

Figure 17. Effect of buoyancy loads on fragility curves for brittle mechanism on the high-rise case-study frame.

\subsection{Discussion}

From comparison of the case-study building performance and fragility curves under tsunami loading, it is clear that shear failure of vertical structural members precipitates collapse. This confirms numerical studies by others (Alam et al. 2018, Petrone et al. 2017, Del Zoppo et al. 2021b) and promotes the retrofit of first storey columns to improve their shear capacity. For the case study buildings, such an intervention alone would more than triple the tsunami inundation depth that the case study buildings can sustain before failing (i.e., comparing collapse fragilities in Figure 13). It is also observed that the structures with blow-out slabs are less fragile than those ones without blow-out slabs. Thus, the adoption of properly designed breakaway holes in interior slabs, suggested in Robertson ${ }^{19}$ for the design on tsunami evacuation shelters, may also represent a suitable retrofit solution for existing buildings, allowing to reduce the uplift loads on the 
structure, whilst better controlling damage (i.e., retaining a portion of the slab and limiting damage induced to other structural elements that might happen under a normal slab uplift failure).

For the particular case-study buildings studied, it is observed that effect of uplift loads on slabs only slightly increases the overall building fragility as compared to the condition where uplift loads and slabs uplift failure are neglected. For the case study buildings analysed this small change seems not to justify the computational effort associated with the use of such kind of refined analysis for fragility assessment. This finding would also suggest that analytical fragility curves produced so far ignoring buoyancy loads are not affected by a significant error due to this omission. However, it is argued here that modelling of buoyancy-induced failure of slabs may have a significant effect on the building direct and indirect loss estimation. Costs related to the repair or replacement of the slabs should be accounted for in the evaluation of direct losses. Indirect losses should also account for the fact that uplift failure of interior slabs will make the building unusable in the aftermath of a tsunami, affecting downtime. As a result, in the case of loss or useability assessment it is very important that the probability of uplift failure of interior slabs (and hence buoyancy-induced loading) is explicitly computed, especially for mid to high rise structures.

\section{Conclusions}

The paper presents a generalised structural analysis methodology for the performance assessment of frames with breakaway infill walls, termed VDPO-BI, able to integrate the tsunami-induced lateral and buoyancy loads on structures, and to account for blow-out slabs. The paper investigates the effects of modelling buoyancy-induced loads and blow-out slabs on the fragility of existing, non-seismically designed, masonry infilled RC frame buildings of different heights. The main findings and conclusions of the study are herein summarized:

- Tsunami-induced buoyancy loads significantly affect the structural performance of buildings under tsunami inundation. For structures with blow-out slabs, the slab uplift failure allows the buildings to achieve a higher lateral capacity, so long as shear failure is avoided;

- The rate of occurrence of blow-out slab failures due to uplift loads increases with the number of stories and reduces when the Froude number increases. However, the occurrence of uplift failure of slabs depends on several other independent factors, namely: the out-of-plane capacity of exterior infill walls, the depth of interior beams, the location of openings in the exterior infill above the slab (that determine water ingress and retention) and the capacity of the slab itself;

- The performance analysis conducted clearly demonstrates that buoyancy-induced loads play a key role in the structural damage evolution during the incremental analysis. Most published studies do not consider buoyancy loads at all, nor do they consider the capacities of slabs or infills. Such studies may result in unrealistic damage 
mechanism predictions, that can compromise the effectiveness of any strengthening strategies designed based on their results.

- A retrofit solution for existing buildings is proposed that combines (1) the shear strengthening of first storey columns and (2) the adoption of properly designed breakaway holes in interior slabs to reduce buoyancy-induced uplift loads and hence avoiding the complete uplift failure of elevated slabs.

- In the presented single-building fragility curves, buoyancy-induced uplift loads on slabs are seen to only slightly increase the fragility of the investigated case-study frames with respect to the case where buoyancy loads are neglected during the VDPO-BI analysis. However, neglecting buoyancy loads from the fragility assessment does not allow for a proper estimation of economic losses. Indeed, the uplift failure of interior slabs can cause significant direct and indirect losses associated with the serviceability of the building in the aftermath of a tsunami that need to be accounted for during a loss assessment. Hence, uplift loads and slabs uplift failures should be considered for probabilistic tsunami risk assessment.

The presented conclusions promote the inclusion of buoyancy-loading in the tsunami assessment of buildings, and although they are based on a limited number of case study applications, they make engineering sense. Further case-study applications will be required to test the generality of the conclusions for other buildings, different tsunami inundation conditions, and in the presence of tsunami induced scour or debris accumulation.

\section{Acknowledgements}

This study was performed in the framework of the research project AWARE - Assessment of structures Waves REsistance during tsunami (PI Dr Del Zoppo). The stay of Dr Del Zoppo at University College London (UCL) was financially supported by UniNA and Compagnia di San Paolo, in the frame of Programme STAR. Prof Ian Robertson of University Manoa is thanked for his insights and discussions on this topic.

\section{References}

Alam MS, Barbosa AR, Scott MH, Cox DT, van de Lindt JW. 2018. Development of physics-based tsunami fragility functions considering structural member failures. Journal of Structural Engineering; 144(3): 04017221.

Alam MS, Winter AO, Galant G, Shekhar K, Barbosa AR, Motley MR et al. 2020. Tsunami-Like Wave-Induced Lateral and Uplift Pressures and Forces on an Elevated Coastal Structure. Journal of Waterway, Port, Coastal, and Ocean Engineering; 146(4): 04020006.

ASCE (2017), Minimum Design Loads and Associated Criteria for Buildings and Other Structures. ASCE/SEI 7-16. Reston, VA, USA. 
Attary N, van de Lindt JW, Unnikrishnan VU, Barbosa AR, Cox DT. 2017. Methodology for development of physicsbased tsunami fragilities. Journal of Structural Engineering; 143(5).

Baiguera M, Rossetto T, Robertson IN, Petrone C. 2019. Towards a tsunami nonlinear static analysis procedure for the ASCE 7 standard. ICONHIC 2019 2nd International Conference on Natural Hazards \& Infrastructure, Chania, Greece.

Borzi B, Pinho R, Crowley H. 2008. Simplified pushover-based vulnerability analysis for large-scale assessment of RC buildings. Eng Struct; 30(3):804-20.

Charvet I, Macabuag J, Rossetto T. 2017. Estimating tsunami-induced building damage through fragility functions: critical review and research needs. Frontiers in built environment; 3-36.

Chaudhary B, Hazarika H, Ishibashi I, Abdullah A. 2017. Sliding and overturning stability of breakwater under combined effect of earthquake and tsunami. Ocean engineering; 136: 106-116.

Chock G, Robertson I, Kriebel D, Francis M, Nistor I. 2013. Tohoku, Japan, earthquake and tsunami of 2011: Performance of structures under tsunami loads. American Society of Civil Engineers.

Comité Européen de Normalisation. 2005. Eurocode 8, Design of structures for earthquake resistance — Part 3: Assessment and retrofitting of buildings. EN 1998-1, CEN, Brussels.

Del Zoppo M, Rossetto T, Di Ludovico M, Prota A, Robertson I. 2020. Structural Response Under Tsunamiinduced Vertical Loads. Proceedings of the 17th World Conference on Earthquake Engineering, 17WCEE, Sendai, Japan.

Del Zoppo M, Rossetto T, Di Ludovico M, Prota A. 2019. Assessing the effect of tsunami-induced vertical loads on RC frames. Proceedings of $1^{\text {st }}$ fib Italy YMG Symposium on Concrete and Concrete Structures, pp. 206-212.

Del Zoppo M, Di Ludovico M, Prota A. 2021a. Methodology for Assessing the Performance of RC Structures with Breakaway Infill Walls under Tsunami Inundation. ASCE Journal of Structural Engineering; 147(2): 04020330.

Del Zoppo M, Wijesundara K, Rossetto T, Dias P, Baiguera M, Di Ludovico M, Thamboo J, Prota A. 2021 b. Influence of exterior infill walls on the performance of RC frames under tsunami loads: Case study of school buildings in Sri Lanka. Engineering Structures; 234: 111920.

EN 1992-1-1 (2004) (English): Eurocode 2: Design of concrete structures - Part 1-1: General rules and rules for buildings.

FEMA. (2017). Hazus tsunami model technical guidance. 

joints. Report EERC 83-19, Earthquake Engineering Research Center, University of California, Berkeley.

Foster ASJ, Rossetto T, Allsop W. 2017. An experimentally validated approach for evaluating tsunami inundation forces on rectangular buildings. Coastal Engineering; 128: 44-57.

Ghobarah A, Saatcioglu M, Nistor I. 2006. The impact of the 26 December 2004 earthquake and tsunami on structures and infrastructure. Engineering structures; 28(2): 312-326.

Hartana, Murakami K. 2015. Numerical and experimental simulation of two-phase tsunami flow through buildings with openings. Journal of Earthquake and Tsunami; 9(03): 1550007.

Jirsa J, Karsan I. 1969. Behavior of concrete under compressive loadings. Journal of structural Division; 95(12): 2543-2563.

McKenna F, Fenves GL, Filippou FC. 2010. OpenSees. University of California, Berkeley. Parisi F, Sabella G. 2017. Flow-type landslide fragility of reinforced concrete framed buildings. Engineering Structures; 131: 28-43.

Park H, Cox DT, Barbosa AR. 2017. Comparison of inundation depth and momentum flux based fragilities for probabilistic tsunami damage assessment and uncertainty analysis. Coastal Engineering; 122: 10-26.

Paulik R, Gusman A, Williams JH, Pratama GM, Lin SL, Prawirabhakti A, Suwarni NWI. 2019. Tsunami hazard and built environment damage observations from Palu City after the September 282018 Sulawesi earthquake and tsunami. Pure and Applied Geophysics; 176(8): 3305-3321.

Petrone C, Rossetto T, Goda K. 2017. Fragility assessment of a RC structure under tsunami actions via nonlinear static and dynamic analyses. Engineering Structures; 136: 36-53.

Petrone C, Rossetto T, Baiguera M, De la Barra Bustamante C, Ioannou I. 2020. Fragility functions for a reinforced concrete structure subjected to earthquake and tsunami in sequence. Engineering Structures; 205: 110120.

Priestley M.J.N., Seible F., Calvi G.M. (1996). Seismic design and retrofit of bridges. John Wiley \& Sons, Inc.

Popovics S. 1973. A numerical approach to the complete stress strain curve for concrete. Cement and concrete research; 3(5): 583-599.

Reggio Decreto 16/11/1939 n. 2229. Norme per la esecuzione delle opere in conglomerato cementizio semplice e armato. G.U. n. 92 del 18/04/1940 [in Italian]. 

Publications. subjected to earthquakes and tsunami. In European Conference on Earthquake Engineering, Thessaloniki, Greece: 545-562. Sumatra earthquake and Indian Ocean tsunami. Earthquake Spectra; 22(3_suppl): 295-319.

Spacone E, Filippou F, Taucer F. 1996. Fiber beam-column model for non-linear analysis of R/C frames: Part I. Formulation. Earthquake Engineering Structural Dynamics; 25: 711-725. Tohoku earthquake. Earthquake Spectra; 32(4); 1989-2007.

Wüthrich D, Pfister M, Nistor I, Schleiss AJ. 2018. Experimental study on forces exerted on buildings with openings due to extreme hydrodynamic events. Coastal Engineering; 140: 72-86.

\section{Statements and Declarations}

The stay of Dr Del Zoppo at University College London (UCL) was financially supported by UniNA and Compagnia di San Paolo, in the frame of Programme STAR.

The authors have no relevant financial or non-financial interests to disclose.

All authors contributed to the study conception and design. Material preparation, data collection and analysis were performed by Marta Del Zoppo. The first draft of the manuscript was written by Marta Del Zoppo and all authors commented on previous versions of the manuscript. All authors read and approved the final manuscript.

The datasets generated during the current study are available from the corresponding author on reasonable request. 